\title{
Striking a balance: $\mathrm{PIP}_{2}$ and $\mathrm{PIP}_{3}$ signaling in neuronal health and disease
}

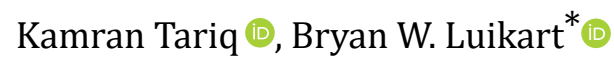 \\ Department of Molecular and Systems Biology, Geisel School of Medicine at Dartmouth, Hanover, NH 03755, USA
}

*Correspondence: Bryan W. Luikart, Department of Molecular and Systems Biology, Geisel School of Medicine at Dartmouth, Hanover, NH 03755, USA. Bryan.W.Luikart@Dartmouth.edu

Academic Editor: Ta-Yuan Chang, Geisel School of Medicine at Dartmouth, USA; Rafael Franco, Universidad de Barcelona, Spain Received: July 23, 2021 Accepted: September 3, 2021 Published: October 29, 2021

Cite this article: Tariq K, Luikart BW. Striking a balance: $\mathrm{PIP}_{2}$ and $\mathrm{PIP}_{3}$ signaling in neuronal health and disease. Explor Neuroprot Ther. 2021;1:86-110. https://doi.org/10.37349/ent.2021.00008

\begin{abstract}
Phosphoinositides are membrane phospholipids involved in a variety of cellular processes like growth, development, metabolism, and transport. This review focuses on the maintenance of cellular homeostasis of phosphatidylinositol 4,5-bisphosphate ( $\mathrm{PIP}_{2}$ ), and phosphatidylinositol 3,4,5-trisphosphate $\left(\mathrm{PIP}_{3}\right)$. The critical balance of these PIPs is crucial for regulation of neuronal form and function. The activity of PIP ${ }_{2}$ and $\mathrm{PIP}_{3}$ can be regulated through kinases, phosphatases, phospholipases and cholesterol microdomains. $\mathrm{PIP}_{2}$ and $\mathrm{PIP}_{3}$ carry out their functions either indirectly through their effectors activating integral signaling pathways, or through direct regulation of membrane channels, transporters, and cytoskeletal proteins. Any perturbations to the balance between PIP $_{2}$ and PIP $_{3}$ signaling result in neurodevelopmental and neurodegenerative disorders. This review will discuss the upstream modulators and downstream effectors of the PIP ${ }_{2}$ and PIP 3 signaling, in the context of neuronal health and disease.
\end{abstract}

\section{Keywords}

Phosphoinositides, cholesterol, autism, Alzheimer's, ion channels, cytoskeleton, AKT, mammalian target of rapamycin

\section{Introduction}

Phosphoinositides are membrane phospholipids involved in regulation of key cellular processes that range from cell growth, protein metabolism, membrane remodeling, and trafficking, to cell death [1-5]. Traditionally, phosphoinositides have been characterized as precursors to secondary messengers for cellular pathways [6,7], however, evidence for direct roles for these phospholipids in membrane dynamics is also piling up [8]. Chemically, the seven distinct species of phosphoinositides are derived from unique phosphorylations of myo-inositol head group of the phosphatidylinositol (PI) at position 3,4 and 5 hydroxyl residues, either singly or in combination [9]. This addition and removal of phosphate groups is selectively regulated by specific phosphoinositide kinases and phosphatases, which are evolutionarily well-conserved [2].

PI 4,5-bisphosphate $\left[\mathrm{PI}(4,5) \mathrm{P}_{2}\right.$, hereon referred to as $\left.\mathrm{PIP}_{2}\right]$, and PI 3,4,5-trisphosphate $\left[\mathrm{PI}(3,4,5) \mathrm{P}_{3}\right.$, hereon referred to as $\mathrm{PIP}_{3}$ ] are the focus of this review. $\mathrm{PIP}_{2}$ and $\mathrm{PIP}_{3}$ are constituents of plasma membrane and their precisely regulated abundance changes in response to cell intrinsic and/or extrinsic stimuli. The PIP $_{2}$ is 
primarily formed as a result of sequential phosphorylations at position 4 and position 5 hydroxyl residues of PI by PI 4-kinase (PI4K), and PI phosphate kinase (PIPK), respectively. PIP $_{3}$ is generated from PIP $_{2}$ by addition of a phosphate on position 3 hydroxyl residue by Class I phosphoinositide 3-kinase (PI3K). Conversely, dephosphorylation of PIP $_{3}$ into PIP $_{2}$ by phosphatase and tensin homolog deleted on chromosome 10 (PTEN) phosphatase also contributes towards maintenance of a $\mathrm{PIP}_{2} / \mathrm{PIP}_{3}$ homeostasis in the cells (Figure 1). In the nervous system, both $\mathrm{PIP}_{2}$ and $\mathrm{PIP}_{3}$ play essential roles in regulating neuronal morphogenesis, electrical activity, ion channels and neurotransmitters mediated signal transduction, synaptic plasticity, and cytoskeletal remodeling [10-13]. Perturbations to the delicate balance between $\mathrm{PIP}_{2}$ and $\mathrm{PIP}_{3}$ levels result in aberrant neurodevelopment and neurodegenerative diseases, like autism spectrum disorders (ASD) and Alzheimer's disease (AD), among others $[14,15]$. This review discusses the upstream modulators that maintain this $\mathrm{PIP}_{2} / \mathrm{PIP}_{3}$ balance, and downstream mediators that are influenced by it, in the context of neuronal regulation and disease.

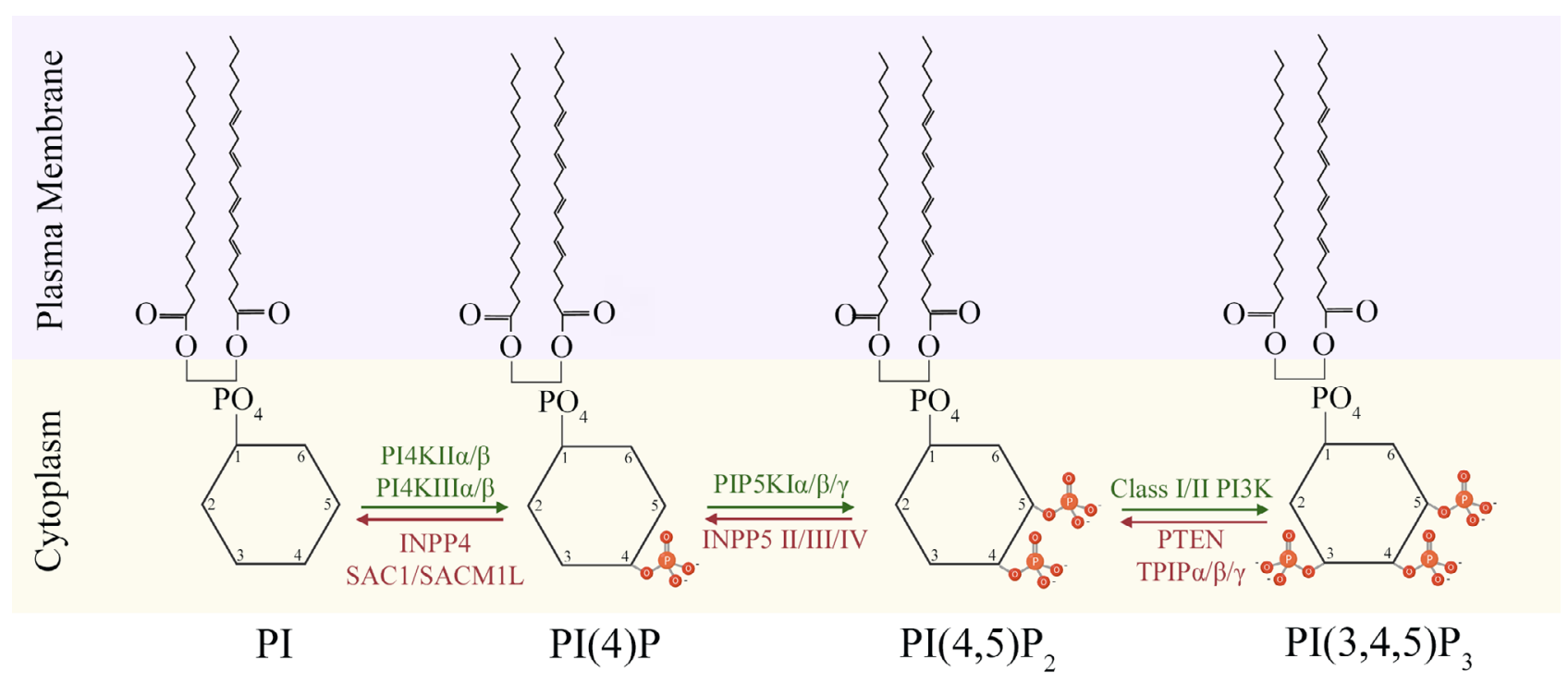

Figure 1. Biosynthesis of $\mathrm{PIP}_{2}$ and $\mathrm{PIP}_{3}$ at plasma membrane-cytoplasm interface. The equilibrium between synthesis of $\mathrm{PIP}_{2}$ and $\mathrm{PIP}_{3}$ at membrane-cytoplasm interface is maintained through addition of phosphate groups (orange) by kinases (green), and its removal by phosphatases (red) at position 3,4, or 5 of the cytoplasmic inositol head group of phosphoinositides (PI). INPP4: inositol polyphosphate 4-phosphatase; SACM1L: SAC1 like phosphatidylinositide phosphatase; INPP5: inositol polyphosphate 5-phosphatase; TPIP: transmembrane phosphatase with tensin homology (TPTE) and PTEN homologous inositol lipid phosphatase

\section{Modulators of PIP $_{2} /$ PIP $_{3}$ balance}

$\mathrm{PIP}_{2}$ and $\mathrm{PIP}_{3}$ are primarily distributed at the cytoplasmic leaflet of plasma membrane and their localized abundance plays diverse roles in regulation of varied cellular processes. A cell needs to maintain a critical balance of these PIs for its normal function. PIP $_{2}$ and PIP ${ }_{3}$ are essential for ligand-associated receptor tyrosine kinase (RTK) and G-protein coupled receptor (GPCR) mediated signaling [16], and their cellular levels and activity can be modulated by PI kinases and PI phosphatases [17], which are described below:

\section{Kinases}

Phosphoinositide kinases are diverse group of enzymes that perform the addition of phosphate group on the hydroxyl residues of myo-inositol ring of PIs. These kinases have substrate specificity for PIs, as well as specificity for their target hydroxyl residue on these PIs.

\section{PI4Ks}

The formation of PIP $_{2}$ is catalyzed by two sequential phosphorylations, first of which is catalyzed by PI4Ks. The two classes of PI4Ks (type II and type III) are categorized into two distinct groups of isozymes, each based on their structure, which lends itself to their specific spatiotemporal activities (Figure 2A). Type II PI4Ks 
are categorized into PI4KII $\alpha$ (gene names are italicized and put in brackets; PI4K2A) and PI4KII $\beta$ (PI4K2B) isozymes, while Type III PI4Ks are categorized into PI4KIII $\alpha$ (PI4KA) and PI4KIII $\beta$ (PI4KB) isozymes [18]. Structurally, type II isozymes have a bisected kinase domain, with its cystine-rich (CR) N-terminal half containing a palmitoylation site, which is likely involved in membrane tethering $[19,20]$. The type II isozymes are homologous but have differences in their N-terminals. PI4KII $\alpha$ contains a proline-rich (PR) region at its N-terminal, while PI4KII $\beta$ contains an acidic region (AR) [21] (Figure 2A). PI4KII $\alpha$ and PI4KII $\beta$ are ubiquitously expressed but PI4KII $\alpha$ has higher expression in brain tissue when compared to PI4KII $\beta$ and its dysfunction is associated with late onset neurodegenerative disease in mouse models [21, 22]. Both PI4KII $\alpha$ and PI4KII $\beta$ localize to intracellular membranes and have been reported to be involved in cellular vesicle trafficking [23,24]. The association of PI4KII $\alpha$ with synaptic vesicles points to its role in neurotransmission [25].

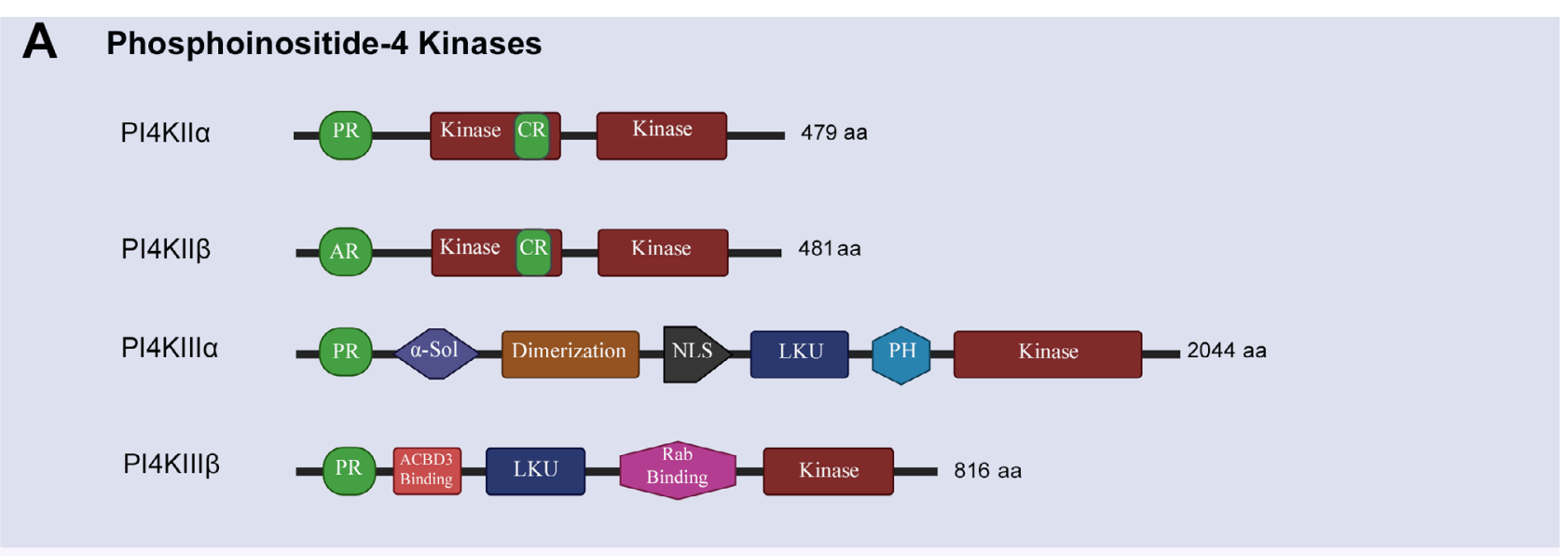

B Phosphatidylinositol Phosphate Kinases

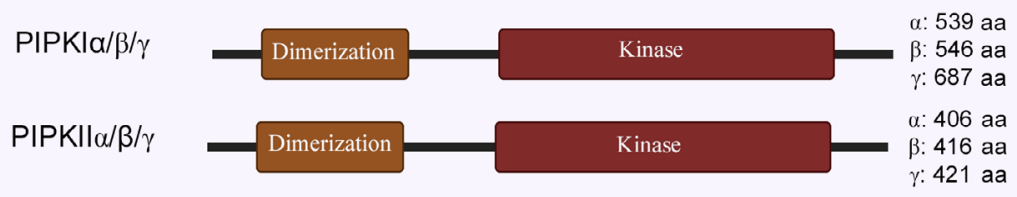

\section{Phosphoinositide-3 Kinases}

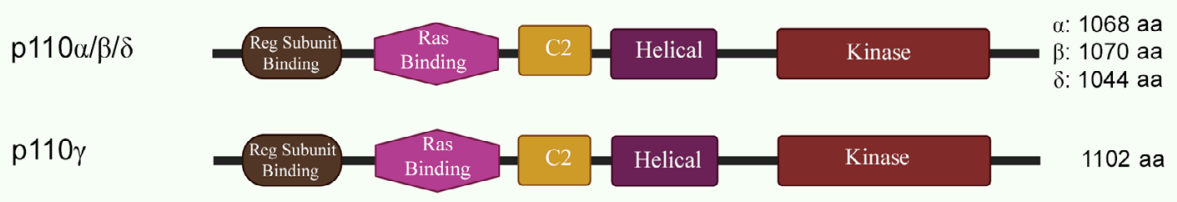

Figure 2. Structural features of phosphoinositide kinases. aa: amino acid; $\alpha$-Sol: $\alpha$-solenoid domain; NLS: nuclear localization signal; LKU: lipid kinase unique; PH: pleckstrin homology domain; ACBD3: acyl-CoA-binding protein 3; Reg: regulatory. The schematics for structural domains are not to scale

The Type III isozyme, PI4KIII $\alpha$ is primarily localized at plasma membrane and is the main source of generation of precursor PIs. Generation of $\mathrm{PIP}_{2}$ from these precursor PIs regulates $\mathrm{Ca}^{2+}$ signaling [26]. Structurally, both type III isozymes contain a N-terminal pleckstrin homology (PH) domain, a LKU domain and a continuous kinase domain on the C-terminal. PI4KIII $\alpha$ contains a large N-terminal solenoid domain ( $\alpha$-Sol), whose role remains unknown [27]. PI4KIII $\alpha$ also contains a NLS and a PH domain, implicated in plasma membrane association [28]. PI4KIII $\beta$ contains a Rab-binding region implicated in lipid transport and membrane trafficking [29].

The activity of type III PI4Ks is specified by their association with a myriad of regulatory binding partners. PI4KIII $\alpha$ directly interacts with tetratricopeptide repeat domain 7 (TTC7)A/B, with FAM126 acting as a scaffold, to form a dimer of heterotrimers [30]. TTC7 interacts with plasma membrane associated 
EFR3 homolog A (EFR3A) protein to activate PI4KIII $\alpha$. On the other hand, PI4KIII $\beta$ interacts with a variety of binding partners of its own, namely Rab11 GTPase, ACBD3, and 14-3-3 regulatory proteins. The Rab11 binding localizes Rab11 to trans-Golgi network (TGN), while the interaction with ACBD3 is reported to be necessary for viral pathogenesis [31]. Protein kinase D mediated S294 phosphorylation stabilizes PI4KIII $\beta$ by allowing the binding of 14-3-3 proteins [29, 32].

\section{PIPKs}

$\mathrm{PIP}_{2}$ can be generated by two different biosynthetic pathways. In the canonical route for synthesis of PIP $_{2}$ a second phosphorylation of PI 4-phosphate (PI4P) at position 5 hydroxyl residue is catalyzed by type I PIPKs (PIPKIs) to generate PIP $_{2}$ [33]. In the non-canonical route, PI 5-phosphate (PI5P) can be phosphorylated by type II PIPKs (PIPKIIs) at position 4 hydroxyl residue to generate same PIP $_{2}$ as well [34]. PI5P is relatively low-abundance and this PIPKII mediated phosphorylation is considered to be a mechanism to regulate its levels in the cell. The Type I PIPKs have three distinct isozymes termed as PIPKI $\alpha$ (PIP5K1A), PIPKI $\beta$ (PIP5K1B), and PIPKI $\gamma$ (PIP5K1C) [33]. The mRNA coding for PIPKI $\gamma$ can be alternatively spliced to give rise to PIPKI $\gamma 635, \gamma 661$ and $\gamma 687$ variants [35]. PIPKIIs are PIPKII $\alpha$ (PIP4K2A), PIPKII $\beta$ (PIP4K2B), and PIPKII $\gamma$ (PIP4K2C) isozymes [36]. Structurally, both types of PIPKs share a homologous central lipid kinase domain (PIPKc) and a conserved dimerization domain. The PIPKc has an activation loop at C-terminal that is specific for substrate and subcellular localization. The variability on $\mathrm{N}$ - and C-terminal also facilitates isoform-specific functions of PIPKs [37] (Figure 2B).

Different homo-dimerization mechanisms have been reported for PIPKIs and PIPKIIs in animal models, giving rise to the idea of different interaction surfaces for their binding partners. The PIPKIs have been reported to be activated by Ras homolog family member A (RhoA)/Rac family small GTPase 1 (Rac1), ADP ribosylation factor 6 (ARF6) GTPases, and Wnt signaling through dishevelled segment polarity protein (DVL), in an isoform-selective manner [38-40]. PIP5KII's isoforms, on the other hand, can form both homo- and heterodimers which may modulate its activity. The activity of PIPKII $\alpha$ is modulated by phosphorylation of its activation loop by protein kinase $\mathrm{D}$, while the activity of PIPKII $\beta$ is regulated by $\mathrm{p} 38$ mitogen activated protein kinase (MAP kinase) [41-43]. PIPKII $\beta$ is also proposed as a GTP sensor in cells, because of its preference for GTP instead of ATP [44]. Not much is known when it comes to regulation of PIPKIl $\gamma$ activity, due to it being non-functional when expressed in bacterial cells [45]. Both types of PIPKs play important role in development, actin dynamics, autophagy, and polarity of cells $[17,46]$. A type III class of PIPKs (PIPKIII, or PIKfyve) also exists which is involved in phosphorylating PI and PI3P at position 5 hydroxyl residue to produce PI5P and $\mathrm{PI}(3,5) \mathrm{P}_{2}$ respectively, but its characterization is beyond the scope of this review.

\section{PI3K}

The PI3Ks are divided into three classes based on their structure and substrate specificity. Class I PI3K catalyzes phosphorylation of position 3 hydroxyl residue of PIP ${ }_{2}$ to generate PIP $_{3}$. Based on their structure and composition, Class I PI3Ks are further divided into two subclasses i.e., Class IA PI3Ks and Class IB PI3Ks. Class IA PI3Ks are heterodimeric proteins consisting of a catalytic subunit p110 $\alpha, \mathrm{p} 110 \beta$, or $\mathrm{p} 110 \delta$; encoded by $P I K 3 C A / B / D$ genes and a regulatory subunit (p85/55/50 $\alpha$, p85 $\beta$, or p55 $\gamma$ variants; encoded by PIK3R1/2/3 genes respectively) $[47,48]$. These regulatory subunits play important role in stabilizing the catalytic subunits, inhibiting their activity, and recognize the phosphorylated YXXM motif on intracellular receptors and adaptors through their Src homology 2 (SH2) domains to allow for plasma membrane localization,

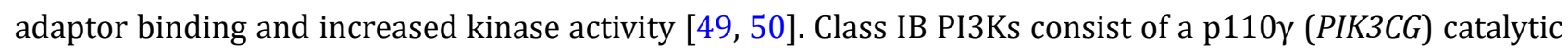
subunit, which can associate with either p101 (PIK3R5), or p84 (also known as p87; PIK3R6) regulatory subunits to form a heterodimer that can get activated through interaction with G $\beta \gamma$ subunits of GTP-binding proteins [51]. In fact, both subclasses can be activated through interaction of GTP-Ras at the Ras-binding domain. The $\mathrm{C} 2$ and helical domains are thought to take part in membrane tethering [52] (Figure 2C).

The ability to generate $\mathrm{PIP}_{3}$ depends on the tissue specific expression and activation of the specific isoforms by the RTKs and GPCRs. There is considerable overlap in RTKs and GPCRs mediated downstream signaling, leading to synergistic activation of different PI3K isoforms [53]. In the context of neurons, the p110 $\alpha$ subunit 
is mainly activated through RTKs and plays important role in insulin signaling which is important for cell survival, energy metabolism, synaptic development, and plasticity [54-56]. The p110 $\beta$ subunit is primarily associated with GPCRs and is reported to regulate glutamate receptor dependent (mGlu1/5) form of plasticity and protein synthesis in the brain $[57,58]$. The P110 $\gamma$ has been implicated in $N$-methyl- $D$-aspartate (NMDA)dependent neuronal plasticity, while $\mathrm{P} 110 \delta$ seems to be involved in axonal growth and regeneration $[59,60]$.

\section{Phosphatases}

Phosphoinositide phosphatases are enzymes that catalyze removal of phosphate groups from the position 3,4 or 5 hydroxyl residues of myo-inositol ring of PIs. Just like PI kinases, these phosphatases also have substrate and catalytic site specificity. Here, phosphatases that recognize only $\mathrm{PIP}_{2}$ or $\mathrm{PIP}_{3}$ as their substrates are in focus.

\section{Phosphoinositide 3-phosphatases}

Phosphoinositide 3-phosphatases (PI3 phosphatases) primarily dephosphorylate $\mathrm{PIP}_{3}$ on position 3, thereby antagonizing the activity of Class I PI3 kinases and generating PIP ${ }_{2}$. The activity of these phosphatases is important for maintaining a $\mathrm{PIP}_{2} / \mathrm{PIP}_{3}$ balance and even small changes may have dramatic effects on neuronal growth and development. The PI3 phosphatases include PTEN, TPTE, and TPIP. PTEN is a dual-specificity lipid and protein phosphatase. Structurally, PTEN contains a CX5R catalytic motif in its phosphatase domain which is common to all PI3 phosphatases; a lipid-binding C2 domain which mediates membrane binding; two C-terminal PEST (proline, glutamine, serine, threonine) sequences that enhance sensitivity to proteolysis; and a PDZ domain important for stability and binding proteins [61] (Figure 3A). PTEN is distributed throughout the cell but has the highest catalytic activity when associated with membranes [62]. Nuclear-associated PTEN has tumor-suppressor activity [63], while nuclear-excluded PTEN has been associated with dysregulation of neuronal growth [64]. PTEN gene activity is reported to be modulated by its splice variants and post transcriptional modifications [65]. Whether PTEN can access nuclear phospholipids is currently a debated topic in the literature.

TPTE (TPTE) is found in plasma membrane but is reported to lack PI phosphatase activity [66]. TPIP (TPTE2) exists as three isoforms (TPIP $\alpha, \beta$ and $\gamma$ ). TPIP $\alpha$ is endoplasmic reticulum (ER)-localized while TPIP $\gamma$ is reported to be cytosolic [67]. All isoforms have a phosphatase domain and a C2 domain. TPIP $\alpha$ and TPIP $\gamma$ are predicted to have transmembrane (TM) segments that display homology to voltage-sensing phosphatases (VSP) $[67,68]$. The best characterized VSP is found in marine invertebrate Ciona intestinalis, which contains a voltage sensing domain (VSD). This ci-VSP recognizes both $\mathrm{PIP}_{3}$ and $\mathrm{PIP}_{2}$ as its substrate for dephosphorylation and gets activated in response to membrane depolarization [69].

\section{Phosphoinositide 4-phosphatases}

Phosphoinositide 4-phosphatases (PI4 phosphatases) catalyze the removal of phosphorylation from position 4 of myo-inositol has group of PIs. Two types of PI4 phosphatases have been identified in mammals, namely INPP4 and TMEM55. Out of these two, only TMEM55 proteins (TMEM55A,TMEM55B; encoded by TMEM55A/B) will be discussed as they recognize $\mathrm{PIP}_{2}$ as their substrate to dephosphorylate position 4 , converting it into PI5P [17]. Both TMEM55A and TMEM55B proteins are expressed ubiquitously; contain a CX5R motif in their phosphatase domain, and are named after two TM segments on their C-terminal [70] (Figure 3B). TMEM55 proteins are not well-characterized but have been reported to be involved in embryonic growth factor receptor (EGFR) degradation, cholesterol homeostasis, DNA damage response and p53-mediated cell death [70-73].

\section{Phosphoinositide 5-phosphatases}

Phosphoinositide 5-phosphatases (PI5 phosphatases) are the most abundant lipid phosphatases. There are three classes (II, III, and IV) of INPP5s with an inositol 5-phosphatase (5-Ptase) domain, which contains motifs for phosphoinositide substrate selectivity $[74,75]$. The type II enzymes are synaptojanins, ORCL1, INPP5B, INPP5], and SKIP. Both synaptojanin isozymes (SYNJ1 and SYNJ2), including their splice variants $(145,170, A, B 1, B 2)$, share similar structures consisting of a N-terminal Sac domain, a central 5-Ptase domain 
and a C-terminal PR region. All synaptojanins dephosphorylate $\mathrm{PIP}_{2}$ and $\mathrm{PIP}_{3}$ on position 5 [76, 77]. Both SYNJ1-145 and SYNJ2B are reported to be especially localized in nerve terminals and synapsis $[78,79]$. The ORCL1 (ORCL) also removes the 5-phosphate from PIP ${ }_{2}$ and PIP ; $_{3}$ contains 5-Ptase, ASH and Rho-GAP-like domains; but only one of its splice variants (ORCL1a) is expressed in brain [80-82]. INPP5B (INPP5B) is structurally similar to ORCL, but with an additional CAAX motif on C-terminal [83]. INPP5B expression has not been reported in brain. INPP5J (INPP5), on the other hand, has been detected in brain; contains an additional SKICH domain; and seems to be involved in neurite elongation [84-86]. SKIP (SKIP) itself has a preference for $\mathrm{PIP}_{3}$ as a substrate and is expressed ubiquitously [87].

\section{A Phosphoinositide-3 Phosphatases}

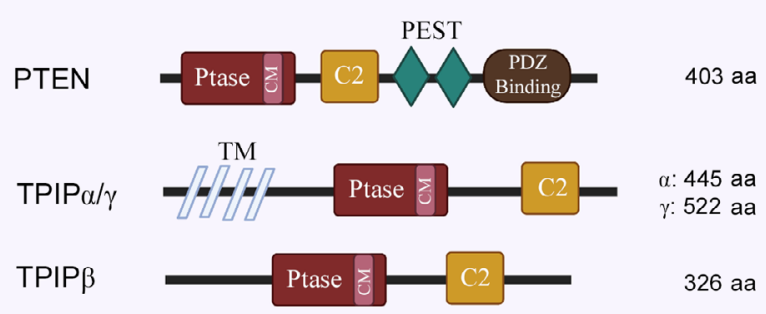

\section{B Phosphoinositide-4 Phosphatases}

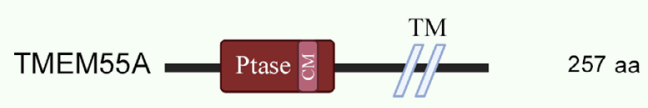

TMEM55B Ptase है 277 aа

\section{Phosphoinositide-5 Phosphatases}

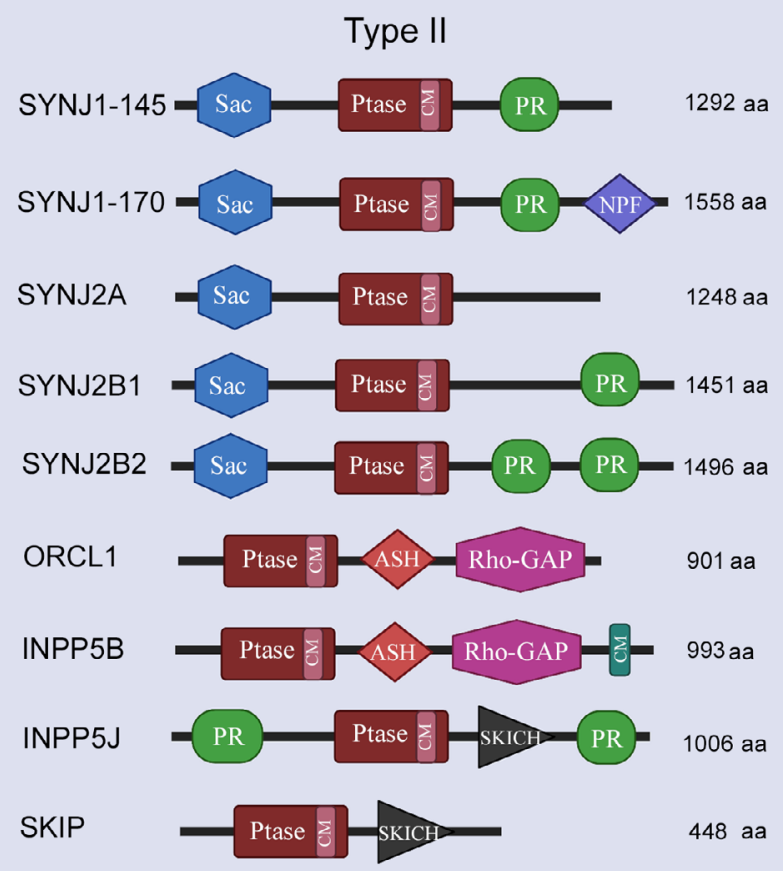

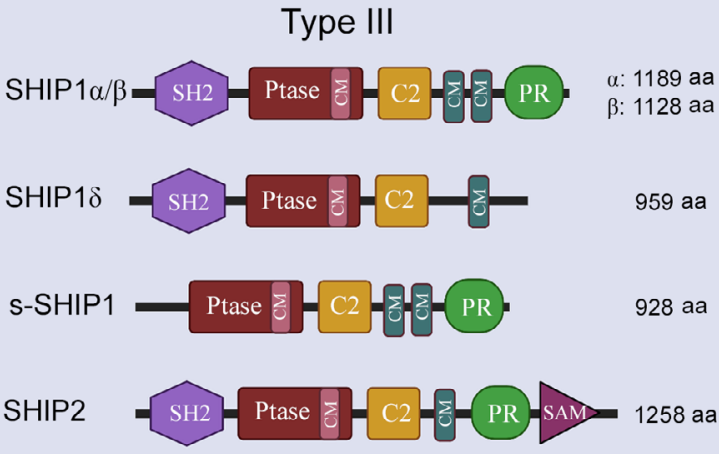

Type IV

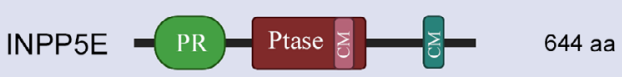

Others

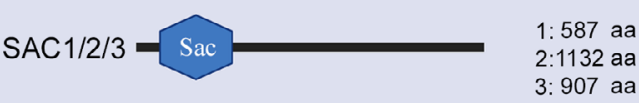

Figure 3. Structural features of phosphoinositide phosphatases. Ptase: phosphatase domain; CM: consensus motif; PEST: proline, glutamine, serine, threonine-rich sequence; TM: transmembrane spanning region; NPF: asparagine, proline, phenylalanine repeats; SKICH: skeletal muscle- and kidney-enriched inositol polyphosphate phosphatase (SKIP) carboxyl hydroxy domain; SH2: Src homology 2 domain; SAM: sterile a motif; SYNJ: synaptojanin; ORCL1: oculocerebrorenal syndrome of Lowe-1; ASH: ASPM-SPD-2-Hydin; Rho-GAP: Rho GTPase activating protein; SHIP: SH2 containing inositol phosphatase; s-SHIP: stem cell specific isoform of SHIP. The schematics for structural domains are not to scale

SHIP family enzymes (SHIP1 and SHIP2) are type III PI5 phosphatases whose alternative splicing gives rise to SHIP1 $\alpha$, SHIP1 $\beta$, SHIP1 $\gamma$ and s-SHIP1 [88]. All SHIP family enzymes contain an SH2 domain, a PR region, and a NPXY motif whose phosphorylation allows for interactions with binding partners containing immunoreceptor tyrosine inhibitory motif (ITIM)/ immunoreceptor tyrosine activating motif (ITAM), phosphotyrosine-binding (PTB) or SH2 domains. SHIP2 also has an additional SAM domain $[17,89]$. All SHIP1 isoforms and SHIP2 recognize PIP ${ }_{3}$ as their substrate, however, only SHIP2 is 
expressed ubiquitously [90]. Pharbin (INPP5E) is the only type IV PI5 phosphatase, contains a PR region, 5-Ptase domain and a CAAX motif; is expressed in brain; and has the highest affinity $\left(K_{\mathrm{m}}=0.65 \mu \mathrm{mol} / \mathrm{L}\right.$ for $\mathrm{PIP}_{3}$ recognition as a substrate than any other PI5 Phosphatase [91]. Another family of PI5 phosphatases is Sac family of phosphatases (Sac1, Sac2, Sac3), which differ from the rest by the lack of 5-Ptase domain. Sac2 and Sac3 dephosphorylate both $\mathrm{PIP}_{2}$ and $\mathrm{PIP}_{3}$ [92] (Figure 3C). Sac2 and Sac3 are expressed ubiquitously but Sac2 expression is especially high in the brain tissue. Both Sac2 and Sac3 have been implicated in neuronal outgrowth $[93,94]$.

\section{Phospholipases}

Phospholipases are enzymes that hydrolyze phospholipids into its constituent fatty acids. The most relevant class of phospholipases to our discussion is phospholipase C (PLC) class of PI-specific enzymes, which cleave $\mathrm{PIP}_{2}$ to generate diacylglycerol (DAG) and inositol-1,4,5-triphosphate ( $\left.\mathrm{IP}_{3}\right)$. DAG and $\mathrm{IP}_{3}$ are important secondary messengers that are involved in protein kinase C (PKC) signaling, intra-neuronal calcium $\left(\mathrm{Ca}^{2+}\right)$ signaling, and transcription, among other regulatory roles [6]. PI specific PLCs have been classified into six families $(\beta, \gamma, \delta, \varepsilon, \zeta$, and $\eta$; Figure 4). Alternative splicing reportedly leads to the generation of about 30 isozymes in mammals [95]. All PI specific isozymes have a homologues core consisting of a N-terminal PH domain, four EF domains, a triose phosphate isomerase (TIM) barrel domain (X, Y), and a C-terminal C2 domain $[96,97]$. The subtle structural nuances and specific combinations of these domains can regulate distribution and function of each PLC isozyme. PLC enzymes are activated through either GPCRs $(\beta, \delta$, and $\eta)$, or RTKs ( $\gamma$ and $\zeta$ ), or both $(\varepsilon)$ [98]. Of note here is a suggested role for the nuclear PLC- $\beta 1$ in PIP ${ }_{2}$ hydrolysis, raising questions about the existence of PI signaling in the nucleus [99]. The isoforms PLC- $\delta(1,3,4)$, PLC- $\beta(1,4)$, PLC- $\gamma(1)$, PLC- $\varepsilon$ and PLC- $\eta(1,2)$ are most relevant to nervous system and have been implicated in neurodegenerative disorders [100].

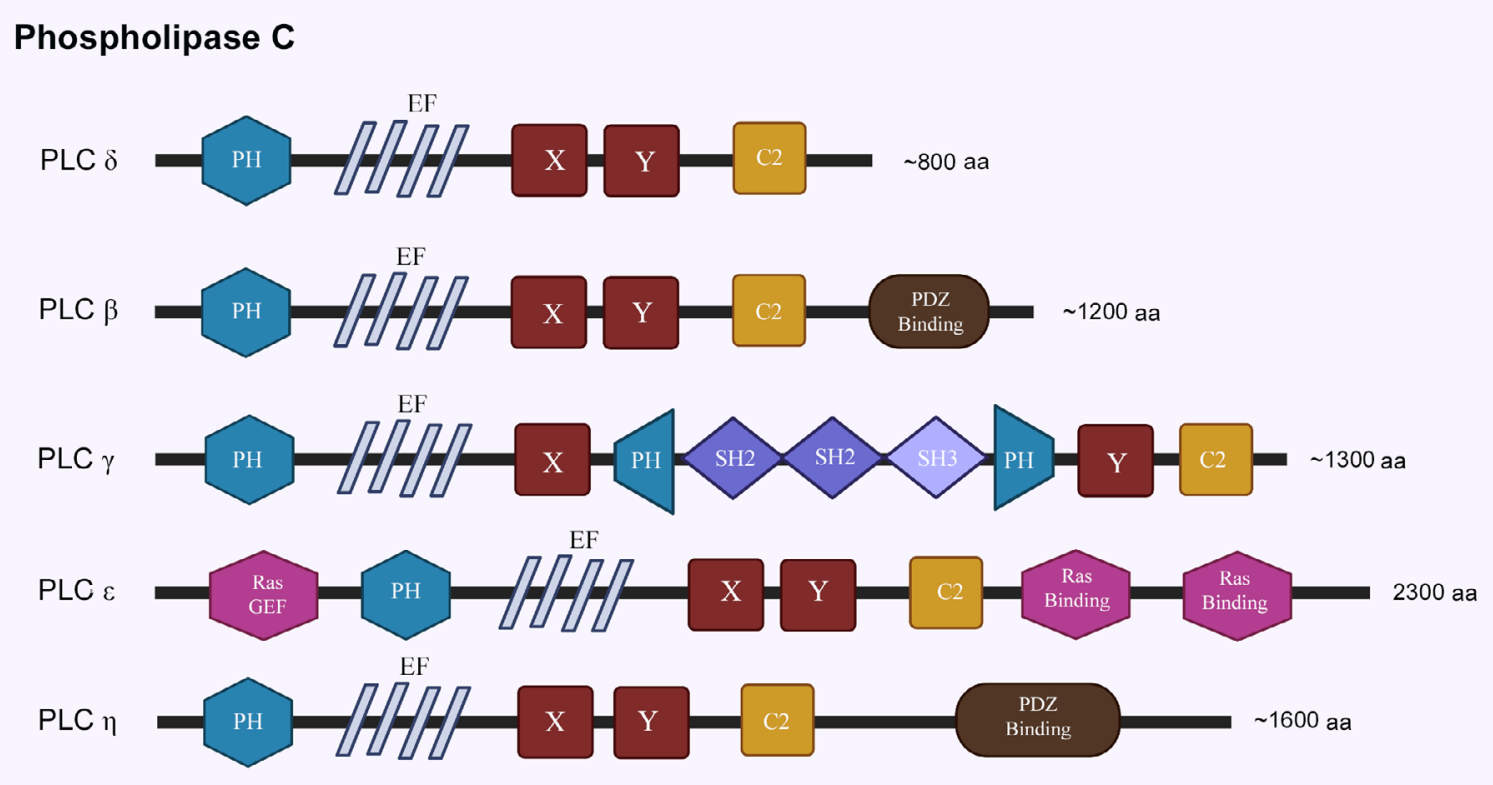

Figure 4. Structural features of phospholipase C family. EF: helix-loop-helix motif; X,Y: TIM barrel domain; SH2: Src homology 2 domain; SH3: Src homology 3 domain. The schematics for structural domains are not to scale

\section{Cholesterol-rich microdomains}

The cellular plasma membranes are heterogenous in nature and are organized into microdomains or ordered/disordered liquid phases, based on their lipid and protein constituents. In the last decade or so, it has been reported that composition of these microdomains dictates localization of PIs to specific regions 
of the plasma membranes [101]. An important regulator of this localization is reported to be cholesterol. Plasma membrane microdomains can be classified, on the basis of cholesterol abundance, into cholesterolrich, liquid-ordered $\left(\mathrm{L}_{\mathrm{o}}\right)$ raft domains or cholesterol-poor, liquid-disordered $\left(\mathrm{L}_{\mathrm{d}}\right)$ non-raft domains. Recent literature suggests that $\mathrm{PIP}_{2}$ is present in both domains, however, it gets hydrolyzed by PLC faster, and is also restored more rapidly in cholesterol-rich $\left(\mathrm{L}_{0}\right)$ domain [102]. This compartmentalization of PIP $_{2}$ signaling seems to be conserved as it has been reported in plants membranes as well [103]. In the context of neurodegenerative diseases, increasing cholesterol levels in the membranes led to PLC-mediated depletion of $\mathrm{PIP}_{2}$ and an increase in AD-associated secretory amyloid $\beta 42$ in cell lines [104]. PTEN phosphatase binding to $\mathrm{PIP}_{2}$ is also reported to be increased in cholesterol-rich environments [105].

\section{Effectors of $\mathrm{PIP}_{2}$ and $\mathrm{PIP}_{3}$ signaling}

Classically, $\mathrm{PIP}_{2}$ and $\mathrm{PIP}_{3}$ were primarily thought of as precursors to secondary messengers that mediate activity of integral cellular signaling pathways through interaction with cytoplasmic proteins. However, $\mathrm{PIP}_{2}$ and $\mathrm{PIP}_{3}$ also play direct roles in mediating the activities of membrane-bound ion channels and transporters. These direct and indirect roles of $\mathrm{PIP}_{2}$ and $\mathrm{PIP}_{3}$ signaling in mediating cellular development and function are described below:

\section{$\mathrm{IP}_{3}$ and DAG signaling}

GPCRs or RTKs mediated activation of PLC isoforms leads to hydrolysis of $\mathrm{PIP}_{2}$ into $\mathrm{IP}_{3}$ and DAG [6]. IP ${ }_{3}$ binds to $\mathrm{IP}_{3}$ receptors $\left(\mathrm{IP}_{3} \mathrm{Rs}\right)$ on the ER to release $\mathrm{Ca}^{2+}$. These $\mathrm{IP}_{3} \mathrm{Rs}$ are found on nuclear envelope as well. In order for $\mathrm{Ca}^{2+}$ to release from ER into the cytosol, $\mathrm{IP}_{3}$ first needs to bind to all four monomers of an $\mathrm{IP}_{3} \mathrm{R}$ tetramer, causing a conformational change that allows $\mathrm{Ca}^{2+}$ to pass. This allowance is, however, transient. When $\mathrm{Ca}^{2+}$ levels rise above a certain level, this signaling becomes inhibitory through complex feedback interactions [106-108]. These $\mathrm{IP}_{3}$ induced $\mathrm{Ca}^{2+}$ oscillations are found in multiple cell types. In brains, these oscillations regulate differentiation and proliferation [109]. $\mathrm{IP}_{3}$ levels regulate steering of axonal growth cones, while $\mathrm{Ca}^{2+}$ transients specify if a neuron will be inhibitory or regulatory by way of regulating neurotransmitters release [110]. Low-frequency oscillations lead to release of excitatory neurotransmitters (acetylcholine, glutamate), while higher frequency oscillations lead to expression of inhibitory transmitters (glycine, $\gamma$-aminobutyric acid) [111]. These oscillations are important in generating brain rhythms for sleep/ wake cycle, memory formation, and synaptic plasticity $[112,113]$. Alterations in $\mathrm{IP}_{3} / \mathrm{Ca}^{2+}$ signaling are associated with many neurological disorders like AD, ASD, epilepsy, schizophrenia among others, which are discussed in section Disease relevance.

DAG, the second product of $\mathrm{PIP}_{2}$ hydrolysis, is most notably involved in PKC signaling. The PKC family of kinases have two DAG-binding copies of $\mathrm{C} 1$ domains, and in the case of conventional PKCs (cPKCs), an additional $\mathrm{C} 2$ domain to sense intracellular $\mathrm{Ca}^{2+}$ levels for full activation $[114,115]$. The subcellular distribution of cPKCs is cytosolic under basal $\mathrm{Ca}^{2+}$ conditions, and it has now been shown that $\mathrm{Ca}^{2+}$ binding to $\mathrm{C} 2$ domain is sufficient and necessary for rapid membrane translocation. The DAG association with C1 domain of cPKC is important for its retention on the membrane [116]. Hence, the downstream signaling of both $\mathrm{PIP}_{2}$ hydrolysis products is intricately connected and has critical roles to play in activation of cPKCs. The activation of cPKCs has been implicated in interfering with inhibitory binding of calmodulin at plasma membrane $\mathrm{Ca}^{2+}$-ATPases (PMCA); regulation of transient receptor potential (TRP), $\mathrm{Na}^{+} / \mathrm{Ca}^{2+}$ exchanger (NCX) and sodium proton exchangers (NHE) channels; generation of cyclic adenosine monophosphates (cAMPs); and activation of phospholipase D (PLD) and DAG kinases to coordinate phosphatidic acid (PA) signaling [117-121] (Figure 5). The PA signaling is known to play role in neurite growth associated cytoskeletal and membrane remodeling [122]. Alterations in PA signaling levels are associated with glioblastomas, intellectual disability, and neurodegenerative disorders, which are discussed later. 




Figure 5. Effectors of $\mathrm{PIP}_{2}$ and $\mathrm{PIP}_{3}$. The hydrolysis of PIP by PLC leads to formation of $\mathrm{IP}_{3}$ and DAG which are involved in intracellular calcium release and activation of PKC-mediated signaling. PI3K-mediated synthesis of PIP $_{3}$ leads to activation of AKT/ mammalian target of rapamycin (mTOR) signaling pathway, with mTOR complexes, glycogen synthase kinase 3 (GSK3) $\beta$ and Forkhead BOX O (FOXO) working as main effectors for regulation of processes of protein synthesis, cytoskeletal organization, and nutrient-sensing and survival. PTEN phosphatase keeps this activation in balance by dephosphorylation of PIP into PIP $_{2}$. Activating phosphorylations are shown in green, while inhibitory phosphorylations are shown in red. 4E-BP1: eukaryotic initiation factor 4E-binding protein 1; EIF4E: eukaryotic translation initiation factor 4E; APC: adenomatous polyposis coli; Deptor: DEP domain-containing mTOR-interacting protein; mLST8: mammalian lethal with sec13 protein 8; mSIN1: mammalian stress activated protein kinase interacting protein; mTORC1: mammalian target of rapamycin complex 1; PDK: phosphoinositide-dependent protein kinase; PM: plasma membrane; PRAS40: proline-rich Akt substrate of $40 \mathrm{kDa}$; Raptor: regulatory associated protein of mTOR; Rheb: Ras homolog enriched in brain; Rictor: rapamycin-insensitive companion of mTOR; S6: ribosomal protein S6; S6K: ribosomal S6 kinase; TSC: tuberous sclerosis complex

\section{AKT and mTOR pathway}

Canonically, the activation of RTKs or GPCRs by extracellular stimuli recruits PI3K to plasma membrane, where it catalyzes the phosphorylation of PIP $_{2}$, which generates PIP . This generation of PIP $_{3}$ leads to activation of AKT (also known as protein kinase B)/mTOR signaling pathway, which is a central regulator for cell growth, metabolism, protein translation, cytoskeletal organization, membrane trafficking and survival [123]. PTEN is a negative regulator of this pathway which keeps the activation of this pathway in check, by dephosphorylating $\mathrm{PIP}_{3}$ into $\mathrm{PIP}_{2}$ [124]. The formation of $\mathrm{PIP}_{3}$ recruits $\mathrm{PH}$ domain containing proteins like PDK and AKT to the plasma membrane [125]. The PDK is reported to localize in cholesterol-rich membrane rafts [126]. This close proximity allows PDK to phosphorylate AKT at T308 [127]. Phosphorylation at T308 stabilizes and activates AKT.

For AKT to reach its maximal activity potential a further phosphorylation at $\mathrm{S} 473$ is needed $[128,129]$. It is thought that first phosphorylation event at T308 primes AKT for second phosphorylation at S473, which in turn, stabilizes the first T308 phosphorylation. This idea is supported by the observations that T308 phosphorylation can occur without prior S473 phosphorylation, but not vice versa [130]. The S473 phosphorylation is brought about by mTOR complex 2 (mTORC2). This complex is assembled by PIP 3 binding to the PH-domain containing mSIN1, and thereby relieving its suppression on mTOR kinase activity and localizing it to plasma membrane as well [131]. mTORC2 complex also contains a scaffolding protein Rictor which regulates its assembly. mTORC2, as the name of its scaffolding protein suggests, is insensitive to acute 
rapamycin treatment and is known to regulate cytoskeletal rearrangements to support formation of new dendritic branches $[129,132]$.

Targeting Rictor to inhibit mTORC2 activity has been shown to result in inhibition of basal synaptic transmission and dendritic outgrowth in hippocampal neurons [133]. Another candidate for mediating this S473 phosphorylation on AKT is DNA-dependent protein kinase catalytic subunit (DNA-PKcs), but its role has been described mostly in the context of DNA damage in the nucleus [134]. Reports of PIP ${ }_{3}$ being enriched at endosome and nuclear envelope also support the idea of localized phosphorylation and activation of AKT in intracellular compartments $[135,136]$. In addition, three subtypes of AKT (AKT1, AKT2, AKT3) exist, with a high degree of homology in amino acid sequence and corresponding phosphorylation sites. Mostly, only AKT1 and AKT3 expression has been reported in hippocampus, while AKT2 expression is limited to cerebellum [137].

AKT targets many substrates which are at the nodes of different signaling pathways. One such target protein is GSK3 whose inhibitory phosphorylations of its targets are relieved by an inactivating phosphorylation by AKT. GSK3 regulates cell growth and development by regulating glycogen metabolism. It is also involved in Wnt/ $\beta$-catenin signaling pathway, indicating its role in crosstalk between these two pathways $[138,139]$. Another downstream effect of AKT activation is the assembly of mTORC1. mTORC1 is not a direct substrate of AKT. AKT mediated inhibitory phosphorylation on TSC relieves its inhibition of Rheb-GTP formation and leads to subsequent activation of mTORC1. In addition, mTORC1 complex assembly is facilitated by a scaffolding protein Raptor, whose suppression is relieved by AKT-mediated phosphorylation of PRAS40 [140-142] (Figure 5).

Broadly, mTORC1 is involved in processes of enhanced protein synthesis and growth through downstream effectors like S6 kinase; lipid synthesis through sterol responsive element binding protein (SRBEP); cellular stress responses through its negative regulator AMPK; and cell survival through autophagy and ubiquitin proteosome regulation [143-146]. In neuronal context, mTORC1 is activated through stimuli like brain-derived neurotrophic factor (BDNF), reelin, glutamate, gamma-aminobutyric acid (GABA), acetyl choline, and neuropeptides [147-149]. The stimulation of mTOR increases dendritic protein synthesis locally and contributes to synaptic and structural plasticity $[150,151]$. mTOR activity is also needed for proper dendritic arborization, axonal branching, neuronal polarization, and autophagy mediated differentiation [152-154].

AKT also targets transcription factors of FOXO family. These transcription factors translocate from cytoplasm to nucleus to regulate processes like apoptosis and oxidative stress resistance. In the nervous system, acute FOXO activity is involved in age-dependent axonal degeneration, spine density and consolidation of memories $[155,156]$.

\section{Ion transporters and channels}

Apart from signaling through its downstream effectors, PIP $_{2}$ may directly bind to and interact with ion transporters and membrane channels to affect their activity [11]. The phospholipid composition of the intracellular compartments has been hypothesized to regulate the activity of membrane channels in space, until they arrive at their target membrane compartment with their signature phospholipid composition. Another hypothesis is about regulation of channels' activity in time. Cells may respond dynamically to extracellular stimuli by way of changes in PI signaling mediating cell's electrical and transport activity $[157,158]$. This is an area of active investigation and the exact nature of PI binding to membrane channels has been difficult to determine. However, recent crystallography and mutagenesis studies have identified clusters of conserved amino acid residues on the channels that interact with phosphate group of PIs. These interactions might cause conformational changes to stabilize channel protein in a certain state, as observed with crystal structures of $\mathrm{PIP}_{2}$ bound to potassium channels. The conformational change brought about by binding of $\mathrm{PIP}_{2}$ is thought to lead to channel activation $[159,160]$.

In the context of potassium channels activity, $\mathrm{PIP}_{2}$ seems to be the principal phospholipid regulating their activity. For voltage-gated potassium channels (Kv), the Kv7 or potassium voltage-gated channel subfamily Q (KCNQ) family is most relevant to neuronal excitability [161]. The PLC mediate depletion of 
$\mathrm{PIP}_{2}$ reduces their current in a matter of seconds [159]. Direct application of $\mathrm{PIP}_{2}$ experimentally, slows this rundown [160]. Structurally, basic residues on the C-terminal TM segment and calmodulin binding may be required for $\mathrm{PIP}_{2}$ coupling to KCNQ channels [162]. Inwardly rectifying potassium channels (Kir) were the first to be identified as $\mathrm{PIP}_{2}$ dependent [163]. All members of this family bind to $\mathrm{PIP}_{2}$, but do so with different affinities (high affinity: Kir1, 2.1 and 4; low affinity: Kir2.3 and 3). High affinity channels were slowest to run down in response to $\mathrm{PIP}_{2}$ depletion [164]. $\mathrm{PIP}_{2}$ stabilizes the open state of these channels by binding to basic and hydrophobic residues in the N- and distal C-terminal [165].

Calcium activated potassium channels have also been shown to regulated by $\mathrm{PIP}_{2}$ levels in the cell $[166,167]$. For voltage-gated calcium channels $(\mathrm{CaV}), \mathrm{PIP}_{2}$ is required for opening in response to membrane potential changes. $\mathrm{PIP}_{2}$ is hypothesized to bind to $\mathrm{CaV}$ as a segmented ligand bringing two parts together, and is competed for interaction by $\mathrm{CaV} \beta$ subunits whose expression governs the $\mathrm{PIP}_{2}$ sensitivity of these channels [168]. Some of the TRP channels are also PIP ${ }_{2}$ sensitive, i.e., PIP $_{2}$ promotes their opening by binding to basic residues on cytoplasmic linker and C-terminal [169, 170]. An example being cold-activated TRPM8 channel is that it does not respond to stimuli in the absence of $\mathrm{PIP}_{2}$ [171]. The P2X receptor, CNG, and TMEM16-ANO1 are examples of some other channels that are also sensitive to $\mathrm{PIP}_{2}$ binding [158].

\section{Actin regulatory proteins}

Actin provides an architectural scaffold for the cell, and is an important regulator of cellular shape, trafficking, and migration [172]. This actin network is integral to the morphological remodeling of highly specialized cells like neurons. PIs regulate the activity of actin-binding proteins which are reported to control the initiation of processes like spinogenesis and dendritogenesis.

In general, $\mathrm{PIP}_{2}$ inactivates actin-biding proteins that inhibit actin polymerization, while activating proteins that support polymerization. Gelsolin is an actin severing protein, whose binding with PIP $_{2}$ frees up the ends of actin filament for polymerization [173]. Interestingly, this binding is enhanced by calcium ions to promote actin polymerization [174]. The actin-related protein 2/3 (Arp2/3) complex which is responsible for branching of actin filaments is also activated through binding of $\mathrm{PIP}_{2}$ with its activation protein, Wiskott-Aldrich syndrome protein (WASP) [175]. PIP ${ }_{2}$ has also been shown to bind to other actin regulatory proteins like cofilin and profilin. The severing action of cofilin is inhibited by binding with PIP $_{2}$, while $\mathrm{PIP}_{2}$-profilin interaction inhibits PLC $\gamma$-mediated hydrolysis of $\mathrm{PIP}_{2}[176,177]$.

The neuronal membrane branching/bending into dendrites, axons or spines is observed to protrude from specialized filopodia like structures which are filled with actin. $\mathrm{PIP}_{2}$ is reported to mediate the formation of these filopodia. $\mathrm{PIP}_{2}$ recruits the inverse bin-amphiphysin-rvs (I-BAR) protein missingin-metastasis (MIM)/MTSS1 and Arp2/3-mediated actin assembly to nucleate the formation of protrusion that are pre-cursors to spinogenesis [178]. Nerve growth factor (NGF) treatment is known to increase the formation of patches that are precursors to the formation of axonal filopodia in a PI3K mediated activity dependent manner [179]. Localized microdomains of PIP ${ }_{3}$ are also reported to be synchronous with formation of these precursor patches that are formed in response to NGF treatment [180]. Application of brain derived neurotrophic factor was reported to enhance PIP ${ }_{3}$ localization to dendritic filopodia as well [181].

\section{Disease relevance}

The intricate balance between the levels of $\mathrm{PIP}_{2}$ and $\mathrm{PIP}_{3}$ is necessary for proper regulation and maintenance of several critical cellular processes in the nervous system. Any perturbation to this balance, be it through kinases or phosphatases, may lead to deficits in brain development and neuronal regulation, manifesting itself in disease and disorders of the nervous system.

\section{Disorders of neurodevelopment}

Mutations in genes encoding for proteins involved in PI synthesis and metabolism have been associated with ASD. Of the kinases involved in $\mathrm{PIP}_{2}$ and $\mathrm{PIP}_{3}$ synthesis, mutations in catalytic and regulatory isoforms of PI3K have been observed to be overrepresented when it comes to disorders affecting brain development [15]. In the context of dysregulation of catalytic subunits of PI3K, mutations in PIK3CA gene have been observed in 
clinical cases of cortical dysplasia and megalencephaly [182]. Another study described missense mutations in gene coding for $\mathrm{p} 110 \alpha$ in a patient with autism and macrocephaly [183]. There is also strong evidence for overexpression of $\mathrm{p} 110 \beta$ catalytic subunit in some cases of autism [184]. This overexpression has been shown to be caused by chromosomal duplication.

More studies have linked a loss of Fragile $X$ mental retardation protein (FMRP) in Fragile $X$ syndrome (FXS) to p110 $\beta$ overexpression [185]. Since p110 $\beta$ mRNA binds to FMRP, this loss of FMRP is associated with increase in $\mathrm{p} 110 \beta$ expression. This increase has been observed in mouse models [185], as well as human patients cell lines [186, 187]. Dysregulation of another p110 $\delta$ subunit of PI3K has also been observed in autism and schizophrenia $[188,189]$. The location for gene coding for $p 110 \gamma$ has been identified as a potential autism susceptible locus [190]. As for the PI3K regulatory subunits, mutations in p85 $\beta$ have been described to be associated with autism and megalencephaly [191]. So far, members of other classes of PI3K (class II and III) that are involved in generation of PIs other than $\mathrm{PIP}_{2}$ and $\mathrm{PIP}_{3}$ have not been shown to be strongly associated with the incidence of autism, further highlighting the importance of maintaining PIP $_{2}$ an $\mathrm{PIP}_{3}$ balance for neuronal health.

In addition to PI3K, PI4K and PIPKs have also been shown to be altered in autism and other related disorders. Deleterious mutations in a regulator of PI4K have been identified in patients with autism [192]. PIPK isoform 3 has been found to be duplicated in patients with developmental delay and autism [193]. Among the phosphatases regulating $\mathrm{PIP}_{2}$ and $\mathrm{PIP}_{3}$ balance, PTEN stands out for its role in developmental delay, autism, and epilepsy [194-196]. In multiple animal model studies, PTEN loss has been shown to cause autism-like phenotypes and behavior [197-199]. PTEN loss associated phenotypes include anxiety, seizures, macrocephaly, and deficits in neuronal migration, growth, electrical activity, and social behavior [197,199-201].

Trisomy of the locus containing SYNJ1 phosphatase has been shown to result in enlarged endosomes in cell lines developed from patients with Down's syndrome (DS) [202]. Other PI phosphatases have not been linked with autism but have been associated with neurodegeneration.

\section{Disorders of neurodegeneration}

The $\mathrm{PIP}_{2} / \mathrm{PIP}_{3}$ balance in the intracellular environment is reported to be perturbed in neurodegenerative disorders like Alzheimer's and Parkinson's [203]. SYNJ1, a PI phosphatase regulating synaptic activity, was observed to be increased in autopsy of adult brains of DS and early-onset AD patients [204]. The excess of SYNJ1 was also found to contribute to memory deficits in mouse models of AD. Reducing this excess experimentally was found to accelerate clearance of Amyloid $\beta(A \beta)$ and associated cognitive decline. In another study, restoring PIP $_{2}$ levels was sufficient to ameliorate such synaptic dysfunction $[205,206]$. Presence of tau protein has also been detected in patients with SYNJ1 mutations [207]. Missense mutation in sac1 domain of SYNJ1 has also been found in patients with early onset PD [208]. These patients experienced tremors and some cortical atrophy as well. Loss-of-function mutations in SYNJ1 have been observed in patients with infantile epileptic encephalopathy [209, 210].

Single nucleotide polymorphism (SNP) in INPP5B phosphatase have been shown to be associated with sporadic amyotrophic lateral sclerosis (ALS) [211]. Loss of function mutations in chorein or vacuolar protein sorting-associated protein 13A (VPS13A) have been found in patients with a rare hereditary genetic disorder called chorea-acanthocytosis (ChAc) [212]. ChAc is characterized by progressive movement disorder, seizures, cognitive difficulties, and neurodegeneration-particularly in striatum [213-215]. The mechanism behind disease pathology has remained puzzling for a while. However, recent studies in neuronal cell cultures and animal models have hinted at a role for PI signaling in the development of ChAc. Chorein is reported to be involved in activation of p85 regulatory subunit of PI3K, with subsequent activation of several downstream kinases [215, 216]. Compromised cytoskeleton and cell-survival was observed in patient-derived neuronal cell cultures containing mutations in chorein [217]. Mutations in genes encoding for $\mathrm{IP}_{3} \mathrm{R}$, for example inositol 1,4,5-trisphosphate receptor type 1 (ITPR1), have been reported in infantile-onset nonprogressive spinocerebellar ataxia (SCA) [218]. SCA are degenerative disorders related to movement control. The dysfunction of $I_{3} R$ leads to aberrant calcium signaling in cerebellar neurons which are implicated in SCA pathogenesis [219]. Mutations in FAM126A gene leading to loss of hyccin/FAM126A protein, a scaffolding 
partner of PIKIII $\alpha$, causes disorders of progressive hypomyelination in central and peripheral nervous system [30]. This hypomyelination manifests in form of leukoencephalopathy known as hypomyelination and congenital cataract (HCC), with symptoms of cognitive deficits and neuropathy [220].

\section{Conclusion}

Phosphoinositide signaling, especially the levels of $\mathrm{PIP}_{2}$ and $\mathrm{PIP}_{3}$, is critically regulated for maintenance of general neuronal health by varied kinases and phosphatases. The downstream functions for PIP $_{2}$ and PIP $_{3}$ are quite diverse, and include roles in neuronal growth, development, connectivity, and activity. Perturbations to the regulators of this balance in $\mathrm{PIP}_{2}$ and $\mathrm{PIP}_{3}$ have been associated with myriad of neurological disorders and diseases. Research in this domain continues and new associations are being discovered regularly. However, the need for effective therapeutic strategies remains.

\section{Abbreviations}

5-Ptase: inositol 5-phosphatase

ACBD3: acyl-CoA-binding protein 3

AD: Alzheimer's disease

ASD: autism spectrum disorder

CaV: voltage-gated calcium channels

ChAc: chorea-acanthocytosis

cPKC: conventional protein kinase $\mathrm{C}$

DAG: diacylglycerol

ER: endoplasmic reticulum

FMRP: Fragile $\mathrm{X}$ mental retardation protein

FOXO: Forkhead BOX 0

GPCR: G-protein coupled receptor

GSK3: glycogen synthase kinase 3

INPP5: inositol polyphosphate 5-phosphatase

$\mathrm{IP}_{3}$ : inositol-1,4,5-triphosphate

$I_{3} R$ : inositol-1,4,5-triphosphate receptor

Kir: inwardly rectifying potassium channels

mTORC1: mammalian target of rapamycin complex 1

mTORC2: mammalian target of rapamycin complex 2

ORCL: oculocerebrorenal syndrome of Lowe

PA: phosphatidic acid

PD: Parkinson's disease

PDK: phosphoinositide-dependent protein kinase

PH: pleckstrin homology

PI: phosphoinositides

PI3K: phosphoinositide 3-kinase

PI4K: phosphatidylinositol-4 kinases

PI5 phosphatases: phosphoinositide 5-phosphatases

PI5P: phosphatidylinositol 5-phosphate

$\mathrm{PIP}_{2}$ : phosphatidylinositol 4,5-bisphosphate

PIP $_{3}$ : phosphatidylinositol 3,4,5-trisphosphate 
PIPK: phosphatidylinositol phosphate kinase

PIPKIIs: type II phosphatidylinositol phosphate kinases

PIPKIs: type I phosphatidylinositol phosphate kinases

PKC: protein kinase $\mathrm{C}$

PLC: phospholipase C

PR: proline-rich

PTEN: phosphatase and tensin homolog deleted on chromosome 10

Rictor: rapamycin-insensitive companion of mTOR

RTK: receptor tyrosine kinase

SCA: spinocerebellar ataxia

SH2: Src homology 2

SHIP: Src homology 2 containing inositol phosphatase

SKIP: skeletal muscle- and kidney-enriched inositol polyphosphate phosphatase

SYNJ: synaptojanin

TM: transmembrane spanning region

TPIP: transmembrane phosphatase with tensin homology and phosphatase and tensin homolog deleted on chromosome 10 homologous inositol lipid phosphatase

TPTE: transmembrane phosphatase with tensin homology

TRP: transient receptor potential

VSP: voltage-sensing phosphatases

\section{Declarations}

Acknowledgments

The authors thank members of the Luikart lab for their intellectual assistance to this paper. Figures were created with BioRender and ChemSketch.

\section{Author contributions}

KT and BWL conceived the manuscript. KT wrote the manuscript, and BWL edited the manuscript.

\section{Conflicts of interest}

The authors declare that they have no conflicts of interest.

\section{Ethical approval}

Not applicable.

\section{Consent to participate}

Not applicable.

\section{Consent to publication}

Not applicable.

\section{Availability of data and materials}

Not applicable. 


\section{Funding}

The authors are funded by the National Institute of Health grant R01 MH097949 to BWL and Autism Speaks grant 11857 to KT. The funders had no role in study design, data collection and analysis, decision to publish, or preparation of the manuscript.

\section{Copyright}

(C) The Author(s) 2021.

\section{References}

1. Phan TK, Williams SA, Bindra GK, Lay FT, Poon IKH, Hulett MD. Phosphoinositides: multipurpose cellular lipids with emerging roles in cell death. Cell Death Differ. 2019;26:781-93.

2. Raghu P, Joseph A, Krishnan H, Singh P, Saha S. Phosphoinositides: regulators of nervous system function in health and disease. Front Mol Neurosci. 2019;12:208.

3. Balla T. Phosphoinositides: tiny lipids with giant impact on cell regulation. Physiol Rev.2013;93:1019-137.

4. Di Paolo G, De Camilli P. Phosphoinositides in cell regulation and membrane dynamics. Nature. 2006;443:651-7.

5. De Matteis MA, Godi A. PI-loting membrane traffic. Nat Cell Biol. 2004;6:487-92.

6. Berridge MJ, Irvine RF. Inositol trisphosphate, a novel second messenger in cellular signal transduction. Nature. 1984;312:315-21.

7. Kirk CJ, Bone EA, Palmer S, Michell RH. The role of phosphatidylinositol 4,5 bisphosphate breakdown in cell-surface receptor activation. J Recept Res. 1984;4:489-504.

8. Falkenburger BH, Jensen JB, Dickson EJ, Suh BC, Hille B. Phosphoinositides: lipid regulators of membrane proteins. J Physiol. 2010;588:3179-85.

9. Kim YJ, Jahan N, Bahk YY. Biochemistry and structure of phosphoinositide phosphatases. BMB Rep. 2013;46:1-8.

10. Zhang SX, Duan LH, He SJ, Zhuang GF, Yu X. Phosphatidylinositol 3,4-bisphosphate regulates neurite initiation and dendrite morphogenesis via actin aggregation. Cell Res. 2017;27:253-73.

11. Suh BC, Hille B. PIP is a necessary cofactor for ion channel function: how and why? Annu Rev Biophys. 2008;37:175-95.

12. Shi SH, Jan LY, Jan YN. Hippocampal neuronal polarity specified by spatially localized mPar3/mPar6 and PI 3-kinase activity. Cell. 2003;112:63-75.

13. Kirchner MK, Foehring RC, Wang L, Chandaka GK, Callaway JC, Armstrong WE. Phosphatidylinositol 4,5-bisphosphate $\left(\mathrm{PIP}_{2}\right)$ modulates afterhyperpolarizations in oxytocin neurons of the supraoptic nucleus. J Physiol. 2017;595:4927-46.

14. Arancio O. PIP 2 : a new key player in Alzheimer's disease. Cellscience. 2008;5:44-7.

15. Gross C. Defective phosphoinositide metabolism in autism. J Neurosci Res. 2017;95:1161-73.

16. Schlessinger J. Cell signaling by receptor tyrosine kinases. Cell. 2000;103:211-25.

17. Sasaki T, Takasuga S, Sasaki J, Kofuji S, Eguchi S, Yamazaki M, et al. Mammalian phosphoinositide kinases and phosphatases. Prog Lipid Res. 2009;48:307-43.

18. Balla A, Balla T. Phosphatidylinositol 4-kinases: old enzymes with emerging functions. Trends Cell Biol. 2006;16:351-61.

19. Barylko B, Gerber SH, Binns DD, Grichine N, Khvotchev M, Südhof TC, et al. A novel family of phosphatidylinositol 4-kinases conserved from yeast to humans. J Biol Chem. 2001;276:7705-8.

20. Jung G, Wang J, Wlodarski P, Barylko B, Binns DD, Shu H, et al. Molecular determinants of activation and membrane targeting of phosphoinositol 4-kinase IIß. Biochem J. 2008;409:501-9. 
21. Balla A, Tuymetova G, Barshishat M, Geiszt M, Balla T. Characterization of type II phosphatidylinositol 4-kinase isoforms reveals association of the enzymes with endosomal vesicular compartments. J Biol Chem. 2002;277:20041-50.

22. Minogue S, Anderson JS, Waugh MG, dos Santos M, Corless S, Cramer R, et al. Cloning of a human type II phosphatidylinositol 4-kinase reveals a novel lipid kinase family. J Biol Chem. 2001;276:16635-40.

23. Waugh MG, Minogue S, Anderson JS, Balinger A, Blumenkrantz D, Calnan DP, et al. Localization of a highly active pool of type II phosphatidylinositol 4-kinase in a p97/valosin-containing-protein-rich fraction of the endoplasmic reticulum. Biochem J. 2003;373:57-63.

24. Wei YJ, Sun HQ Yamamoto M, Wlodarski P, Kunii K, Martinez M, et al. Type II phosphatidylinositol 4-kinase $\beta$ is a cytosolic and peripheral membrane protein that is recruited to the plasma membrane and activated by Rac-GTP. J Biol Chem. 2002;277:46586-93.

25. Guo J, Wenk MR, Pellegrini L, Onofri F, Benfenati F, De Camilli P. Phosphatidylinositol 4-kinase type II $\alpha$ is responsible for the phosphatidylinositol 4-kinase activity associated with synaptic vesicles. Proc Natl Acad Sci U S A. 2003;100:3995-4000.

26. Nakanishi S, Catt KJ, Balla T. A wortmannin-sensitive phosphatidylinositol 4-kinase that regulates hormone-sensitive pools of inositolphospholipids. Proc Natl Acad Sci U S A. 1995;92:5317-21.

27. Wu X, Chi RJ, Baskin JM, Lucast L, Burd CG, De Camilli P, et al. Structural insights into assembly and regulation of the plasma membrane phosphatidylinositol 4-kinase complex. Dev Cell. 2014;28:19-29.

28. Heilmeyer LM Jr, Vereb G Jr, Vereb G, Kakuk A, Szivák I. Mammalian phosphatidylinositol 4-kinases. IUBMB Life. 2003;55:59-65.

29. de GraafP, ZwartWT, van Dijken RAJ, Deneka M,Schulz TKF, Geijsen N, et al. Phosphatidylinositol 4-kinase $\beta$ is critical for functional association of rab11 with the Golgi complex. Mol Biol Cell. 2004;15:2038-47.

30. Baskin JM, Wu X, Christiano R, Oh MS, Schauder CM, Gazzerro E, et al. The leukodystrophy protein FAM126A (hyccin) regulates PtdIns(4)P synthesis at the plasma membrane. Nat Cell Biol. 2016;18:132-8.

31. Sasaki J, Ishikawa K, Arita M, Taniguchi K. ACBD3-mediated recruitment of PI4KB to picornavirus RNA replication sites. EMBO J. 2012;31:754-66.

32. Hausser A, Link G, Hoene M, Russo C, Selchow 0, Pfizenmaier K. Phospho-specific binding of 14-3-3 proteins to phosphatidylinositol 4-kinase III $\beta$ protects from dephosphorylation and stabilizes lipid kinase activity. J Cell Sci. 2006;119:3613-21.

33. Loijens JC, Anderson RA. Type I phosphatidylinositol-4-phosphate 5-kinases are distinct members of this novel lipid kinase family. J Biol Chem. 1996;271:32937-43.

34. Rameh LE, Tolias KF, Duckworth BC, Cantley LC. A new pathway for synthesis of phosphatidylinositol4,5-bisphosphate. Nature. 1997;390:192-6.

35. Giudici ML, Emson PC, Irvine RF. A novel neuronal-specific splice variant of Type I phosphatidylinositol 4-phosphate 5-kinase isoform gamma. Biochem J. 2004;379:489-96.

36. Boronenkov IV, Anderson RA. The sequence of phosphatidylinositol-4-phosphate 5-kinase defines a novel family of lipid kinases. J Biol Chem. 1995;270:2881-4.

37. Rao VD, Misra S, Boronenkov IV, Anderson RA, Hurley JH. Structure of type II $\beta$ phosphatidylinositol phosphate kinase: a protein kinase fold flattened for interfacial phosphorylation. Cell. 1998;94:829-39.

38. Honda A, Nogami M, Yokozeki T, Yamazaki M, Nakamura H, Watanabe H, et al. Phosphatidylinositol 4-phosphate 5-kinase $\alpha$ is a downstream effector of the small G protein ARF6 in membrane ruffle formation. Cell. 1999;99:521-32.

39. Chong LD, Traynor-Kaplan A, Bokoch GM, Schwartz MA. The small GTP-binding protein Rho regulates a phosphatidylinositol 4-phosphate 5-kinase in mammalian cells. Cell. 1994;79:507-13.

40. Hu J, Yuan Q, Kang X, Qin Y, Li L, Ha Y, et al. Resolution of structure of PIP5K1A reveals molecular mechanism for its regulation by dimerization and dishevelled. Nat Commun. 2015;6:8205. 
41. Clarke JH, Irvine RF. Evolutionarily conserved structural changes in phosphatidylinositol 5-phosphate 4-kinase (PI5P4K) isoforms are responsible for differences in enzyme activity and localization. Biochem J. 2013;454:49-57.

42. Hinchliffe KA, Irvine RF. Regulation of type II PIP kinase by PKD phosphorylation. Cell Signal. 2006;18:1906-13.

43. Jones DR, Bultsma Y, Keune WJ, Halstead JR, Elouarrat D, Mohammed S, et al. Nuclear PtdIns5P as a transducer of stress signaling: an in vivo role for PIP4Kbeta. Mol Cell. 2006;23:685-95.

44. Sumita K, Lo YH, Takeuchi K, Senda M, Kofuji S, Ikeda Y, et al. The lipid kinase PI5P4K $\beta$ is an intracellular GTP sensor for metabolism and tumorigenesis. Mol Cell. 2016;61:187-98.

45. Clarke JH, Richardson JP, Hinchliffe KA, Irvine RF. Type II PtdInsP kinases: location, regulation and function. Biochem Soc Symp. 2007;74:149-59.

46. Thapa N, Tan X, Choi S, Lambert PF, Rapraeger AC, Anderson RA. The hidden conundrum of phosphoinositide signaling in cancer. Trends Cancer. 2016;2:378-90.

47. Domin J, Waterfield MD. Using structure to define the function of phosphoinositide 3-kinase family members. FEBS Lett. 1997;410:91-5.

48. Hawkins PT, Anderson KE, Davidson K, Stephens LR. Signalling through Class I PI3Ks in mammalian cells. Biochem Soc Trans. 2006;34:647-62.

49. Backer JM, Myers MG Jr, Shoelson SE, Chin DJ, Sun XJ, Miralpeix M, et al. Phosphatidylinositol 3'-kinase is activated by association with IRS-1 during insulin stimulation. EMBO J. 1992;11:3469-79.

50. Vadas O, Burke JE, Zhang X, Berndt A, Williams RL. Structural basis for activation and inhibition of class I phosphoinositide 3-kinases. Sci Signal. 2011;4:re2.

51. Stephens LR, Eguinoa A, Erdjument-Bromage H, Lui M, Cooke F, Coadwell J, et al. The G $\beta \gamma$ sensitivity of a PI3K is dependent upon a tightly associated adaptor, p101. Cell. 1997;89:105-14.

52. Walker EH, Perisic O, Ried C, Stephens L, Williams RL. Structural insights into phosphoinositide 3-kinase catalysis and signalling. Nature. 1999;402:313-20.

53. Burke JE, Williams RL. Synergy in activating class I PI3Ks. Trends Biochem Sci. 2015;40:88-100.

54. Zhao WQ Alkon DL. Role of insulin and insulin receptor in learning and memory. Mol Cell Endocrinol. 2001;177:125-34.

55. Lee CC, Huang CC, Hsu KS. Insulin promotes dendritic spine and synapse formation by the PI3K/Akt/ mTOR and Rac1 signaling pathways. Neuropharmacology. 2011;61:867-79.

56. Sopasakis VR, Liu P, Suzuki R, Kondo T, Winnay J, Tran TT, et al. Specific roles of the p110 $\alpha$ isoform of phosphatidylinsositol 3-kinase in hepatic insulin signaling and metabolic regulation. Cell Metab. 2010;11:220-30.

57. Gross C, Bassell GJ. Neuron-specific regulation of class I PI3K catalytic subunits and their dysfunction in brain disorders. Front Mol Neurosci. 2014;7:12.

58. Guillermet-Guibert J, Bjorklof K, Salpekar A, Gonella C, Ramadani F, Bilancio A, et al. The p110ß isoform of phosphoinositide 3-kinase signals downstream of $\mathrm{G}$ protein-coupled receptors and is functionally redundant with p110 $\gamma$. Proc Natl Acad Sci U S A. 2008;105:8292-7.

59. Kim JI, Lee HR, Sim SE, Baek J, Yu NK, Choi JH, et al. PI3K $\gamma$ is required for NMDA receptor-dependent long-term depression and behavioral flexibility. Nat Neurosci. 2011;14:1447-54.

60. Eickholt BJ, Ahmed AI, Davies M, Papakonstanti EA, Pearce W, Starkey ML, et al. Control of axonal growth and regeneration of sensory neurons by the p110 PI 3-kinase. PLoS One. 2007;2:e869.

61. Lee JO, Yang H, Georgescu MM, Di Cristofano A, Maehama T, Shi Y, et al. Crystal structure of the PTEN tumor suppressor: implications for its phosphoinositide phosphatase activity and membrane association. Cell. 1999;99:323-34. 
62. Das S, Dixon JE, Cho W. Membrane-binding and activation mechanism of PTEN. Proc Natl Acad Sci U S A. 2003;100:7491-6.

63. Trotman LC, Wang X, Alimonti A, Chen Z, Teruya-Feldstein J, Yang H, et al. Ubiquitination regulates PTEN nuclear import and tumor suppression. Cell. 2007;128:141-56.

64. Fricano-Kugler CJ, Getz SA, Williams MR, Zurawel AA, DeSpenza T Jr, Frazel PW, et al. Nuclear excluded autism-associated phosphatase and tensin homolog mutations dysregulate neuronal growth. Biol Psychiatry. 2018;84:265-77.

65. Fragoso R, Barata JT. Kinases, tails and more: regulation of PTEN function by phosphorylation. Methods. 2015;77-78:75-81.

66. Hsu F, Mao Y. The structure of phosphoinositide phosphatases: insights into substrate specificity and catalysis. Biochim Biophys Acta. 2015;1851:698-710.

67. Walker SM, Downes CP, Leslie NR. TPIP: a novel phosphoinositide 3-phosphatase. Biochem J. 2001;360:277-83.

68. Murata Y, Iwasaki H, Sasaki M, Inaba K, Okamura Y. Phosphoinositide phosphatase activity coupled to an intrinsic voltage sensor. Nature. 2005;435:1239-43.

69. Okamura Y, Murata Y, Iwasaki H. Voltage-sensing phosphatase: actions and potentials. J Physiol. 2009;587:513-20.

70. Ungewickell A, Hugge C, Kisseleva M, Chang SC, Zou J, Feng Y, et al. The identification and characterization of two phosphatidylinositol-4,5-bisphosphate 4-phosphatases. Proc Natl Acad Sci U S A. 2005;102:18854-9.

71. Gozani O, Karuman P, Jones DR, Ivanov D, Cha J, Lugovskoy AA, et al. The PHD finger of the chromatinassociated protein ING2 functions as a nuclear phosphoinositide receptor. Cell. 2003;114:99-111.

72. Zou J, Marjanovic J, Kisseleva MV, Wilson M, Majerus PW. Type I phosphatidylinositol-4,5-bisphosphate 4-phosphatase regulates stress-induced apoptosis. Proc Natl Acad Sci U S A. 2007;104:16834-9.

73. Medina MW, Bauzon F, Naidoo D, Theusch E, Stevens K, Schilde J, et al. Transmembrane protein 55B is a novel regulator of cellular cholesterol metabolism. Arterioscler Thromb Vasc Biol. 2014;34:1917-23.

74. Majerus PW, Kisseleva MV, Norris FA. The role of phosphatases in inositol signaling reactions. J Biol Chem. 1999;274:10669-72.

75. Tsujishita Y, Guo S, Stolz LE, York JD, Hurley JH. Specificity determinants in phosphoinositide dephosphorylation: crystal structure of an archetypal inositol polyphosphate 5-phosphatase. Cell. 2001;105:379-89.

76. Ramjaun AR, McPherson PS. Tissue-specific alternative splicing generates two synaptojanin isoforms with differential membrane binding properties. J Biol Chem. 1996;271:24856-61.

77. Nemoto Y, Arribas M, Haffner C, DeCamilli P. Synaptojanin 2, a novel synaptojanin isoform with a distinct targeting domain and expression pattern. J Biol Chem. 1997;272:30817-21.

78. McPherson PS, Garcia EP, Slepnev VI, David C, Zhang X, Grabs D, et al. A presynaptic inositol-5phosphatase. Nature. 1996;379:353-7.

79. Haffner C, Takei K, Chen H, Ringstad N, Hudson A, Butler MH, et al. Synaptojanin 1: localization on coated endocytic intermediates in nerve terminals and interaction of its $170 \mathrm{kDa}$ isoform with Eps15. FEBS Lett. 1997;419:175-80.

80. Ponting CP. A novel domain suggests a ciliary function for ASPM, a brain size determining gene. Bioinformatics. 2006;22:1031-5.

81. Johnson JM, Castle J, Garrett-Engele P, Kan Z, Loerch PM, Armour CD, et al. Genome-wide survey of human alternative pre-mRNA splicing with exon junction microarrays. Science. 2003;302:2141-4.

82. Peck J, Douglas G 4th, Wu CH, Burbelo PD. Human RhoGAP domain-containing proteins: structure, function and evolutionary relationships. FEBS Lett. 2002;528:27-34. 
83. Jefferson AB, Majerus PW. Properties of type II inositol polyphosphate 5-phosphatase. J Biol Chem. 1995;270:9370-7.

84. Ooms LM, Fedele CG, Astle MV, Ivetac I, Cheung V, Pearson RB, et al. The inositol polyphosphate 5-phosphatase, PIPP, is a novel regulator of phosphoinositide 3-kinase-dependent neurite elongation. Mol Biol Cell. 2006;17:607-22.

85. Mochizuki Y, Takenawa T. Novel inositol polyphosphate 5-phosphatase localizes at membrane ruffles. J Biol Chem. 1999;274:36790-5.

86. Gurung R, Tan A, Ooms LM, McGrath MJ, Huysmans RD, Munday AD, et al. Identification of a novel domain in two mammalian inositol-polyphosphate 5-phosphatases that mediates membrane ruffle localization. The inositol 5-phosphatase skip localizes to the endoplasmic reticulum and translocates to membrane ruffles following epidermal growth factor stimulation. J Biol Chem. 2003;278:11376-85.

87. Ijuin T, Mochizuki Y, Fukami K, Funaki M, Asano T, Takenawa T. Identification and characterization of a novel inositol polyphosphate 5-phosphatase. J Biol Chem. 2000;275:10870-5.

88. Tu Z, Ninos JM, Ma Z, Wang JW, Lemos MP, Desponts C, et al. Embryonic and hematopoietic stem cells express a novel SH2-containing inositol 5'-phosphatase isoform that partners with the Grb2 adapter protein. Blood. 2001;98:2028-38.

89. Lucas DM, Rohrschneider LR. A novel spliced form of SH2-containing inositol phosphatase is expressed during myeloid development. Blood. 1999;93:1922-33.

90. Liu Q, Shalaby F, Jones J, Bouchard D, Dumont DJ. The SH2-containing inositol polyphosphate 5-phosphatase, ship, is expressed during hematopoiesis and spermatogenesis. Blood. 1998;91:2753-9.

91. Kisseleva MV, Wilson MP, Majerus PW. The isolation and characterization of a cDNA encoding phospholipid-specific inositol polyphosphate 5-phosphatase. J Biol Chem. 2000;275:20110-6.

92. Minagawa T, Ijuin T, Mochizuki Y, Takenawa T. Identification and characterization of a sac domaincontaining phosphoinositide 5-phosphatase. J Biol Chem. 2001;276:22011-5.

93. Sbrissa D, Ikonomov OC, Fu Z, Ijuin T, Gruenberg J, Takenawa T, et al. Core protein machinery for mammalian phosphatidylinositol 3,5-bisphosphate synthesis and turnover that regulates the progression of endosomal transport. Novel Sac phosphatase joins the ArPIKfyve-PIKfyve complex. J Biol Chem. 2007;282:23878-91.

94. Yuan Y, Gao X, Guo N, Zhang H, Xie Z, Jin M, et al. rSac3, a novel Sac domain phosphoinositide phosphatase, promotes neurite outgrowth in PC12 cells. Cell Res. 2007;17:919-32.

95. Gresset A, Sondek J, Harden TK. The phospholipase C isozymes and their regulation. Subcell Biochem. 2012;58:61-94.

96. Katan M, Williams RL. Phosphoinositide-specific phospholipase C: structural basis for catalysis and regulatory interactions. Semin Cell Dev Biol. 1997;8:287-96.

97. Yang YR, Follo MY, Cocco L, Suh PG. The physiological roles of primary phospholipase C. Adv Biol Regul. 2013;53:232-41.

98. Rhee SG. Regulation of phosphoinositide-specific phospholipase C. Annu Rev Biochem. 2001;70:281-312.

99. Martelli AM, Gilmour RS, Bertagnolo V, Neri LM, Manzoli L, Cocco L. Nuclear localization and signalling activity of phosphoinositidase C $\beta$ in Swiss 3T3 cells. Nature. 1992;358:242-5.

100. Cocco L, Follo MY, Manzoli L, Suh PG. Phosphoinositide-specific phospholipase C in health and disease. J Lipid Res. 2015;56:1853-60.

101. Johnson CM, Chichili GR, Rodgers W. Compartmentalization of phosphatidylinositol 4,5-bisphosphate signaling evidenced using targeted phosphatases. J Biol Chem. 2008;283:29920-8.

102. Myeong J, Park CG, Suh BC, Hille B. Compartmentalization of phosphatidylinositol 4,5-bisphosphate metabolism into plasma membrane liquid-ordered/raft domains. Proc Natl Acad Sci U S A. 2021;118:e2025343118. 
103. Furt F, König S, Bessoule JJ, Sargueil F, ZallotR, Stanislas T, etal. Polyphosphoinositides are enriched in plant membrane rafts and form microdomains in the plasma membrane. Plant Physiol. 2010;152:2173-87.

104. Chun YS, Oh HG, Park MK, Kim TW, Chung S. Increasing membrane cholesterol level increases the amyloidogenic peptide by enhancing the expression of phospholipase C. J Neurodegener Dis. 2013;2013:407903.

105. Jiang Z, Redfern RE, Isler Y, Ross AH, Gericke A. Cholesterol stabilizes fluid phosphoinositide domains. Chem Phys Lipids. 2014;182:52-61.

106. Parys JB, De Smedt H. Inositol 1,4,5-trisphosphate and its receptors. Adv Exp Med Biol. 2012;740:255-79.

107. Prole DL, Taylor CW. Inositol 1,4,5-trisphosphate receptors and their protein partners as signalling hubs. J Physiol. 2016;594:2849-66.

108. Berridge MJ. Calcium oscillations. J Biol Chem. 1990;265:9583-6.

109. Kang DS, Yang YR, Lee C, Kim S, Ryu SH, Suh PG. Roles of phosphoinositide-specific phospholipase C $\gamma 1$ in brain development. Adv Biol Regul. 2016;60:167-73.

110. Tojima T, Hines JH, Henley JR, Kamiguchi H. Second messengers and membrane trafficking direct and organize growth cone steering. Nat Rev Neurosci. 2011;12:191-203.

111. Berridge MJ. The inositol trisphosphate/calcium signaling pathway in health and disease. Physiol Rev. 2016;96:1261-96.

112. Berridge MJ. Calcium regulation of neural rhythms, memory and Alzheimer's disease. J Physiol. 2014;592:281-93.

113. Inoue T, Kato K, Kohda K, Mikoshiba K. Type 1 inositol 1,4,5-trisphosphate receptor is required for induction of long-term depression in cerebellar Purkinje neurons. J Neurosci. 1998;18:5366-73.

114. Quest AF. Regulation of protein kinase C: a tale of lipids and proteins. Enzyme Protein. 1996;49:231-61.

115. Newton AC. Protein kinase C. Seeing two domains. Curr Biol. 1995;5:973-6.

116. Reither G, Schaefer M, Lipp P. PKC $\alpha$ : a versatile key for decoding the cellular calcium toolkit. J Cell Biol. 2006;174:521-33.

117. Wang KK, Wright LC, Machan CL, Allen BG, Conigrave AD, Roufogalis BD. Protein kinase C phosphorylates the carboxyl terminus of the plasma membrane $\mathrm{Ca}^{2+}$-ATPase from human erythrocytes. J Biol Chem. 1991;266:9078-85.

118. Venkatachalam K, Montell C. TRP channels. Annu Rev Biochem. 2007;76:387-417.

119. Schulze DH, Muqhal M, Lederer WJ, Ruknudin AM. Sodium/calcium exchanger (NCX1) macromolecular complex. J Biol Chem. 2003;278:28849-55.

120. Fujii M, Yi KS, Kim MJ, Ha SH, Ryu SH, Suh PG, et al. Phosphorylation of phospholipase C- $\delta_{1}$ regulates its enzymatic activity. J Cell Biochem. 2009;108:638-50.

121. Halls ML, Cooper DM. Regulation by $\mathrm{Ca}^{2+}$-signaling pathways of adenylyl cyclases. Cold Spring Harb Perspect Biol. 2011;3:a004143.

122. Tanguy E, Wang $Q$, Moine $H$, Vitale N. Phosphatidic acid: from pleiotropic functions to neuronal pathology. Front Cell Neurosci. 2019;13:2.

123. Laplante M, Sabatini DM. mTOR signaling at a glance. J Cell Sci. 2009;122:3589-94.

124. Maehama T, Dixon JE. The tumor suppressor, PTEN/MMAC1, dephosphorylates the lipid second messenger, phosphatidylinositol 3,4,5-trisphosphate. J Biol Chem. 1998;273:13375-8.

125. Risso G, Blaustein M, Pozzi B, Mammi P, Srebrow A. Akt/PKB: one kinase, many modifications. Biochem J. 2015;468:203-14.

126. Gao X, Lowry PR, Zhou X, Depry C, Wei Z, Wong GW, et al. PI3K/Akt signaling requires spatial compartmentalization in plasma membrane microdomains. Proc Natl Acad Sci U S A. 2011;108:14509-14.

127. Kim D, Chung J. Akt: versatile mediator of cell survival and beyond. J Biochem Mol Biol. 2002;35:106-15. 
128. Okuno S, Kitani T, Matsuzaki H, Konishi H, Kikkawa U, Fujisawa H. Studies on the phosphorylation of protein kinase $\mathrm{B}$ by $\mathrm{Ca}^{2+} /$ calmodulin-dependent protein kinases. J Biochem. 2000;127:965-70.

129. Sarbassov DD, Guertin DA, Ali SM, Sabatini DM. Phosphorylation and regulation of Akt/PKB by the rictor-mTOR complex. Science. 2005;307:1098-101.

130. Guertin DA, Stevens DM, Thoreen CC, Burds AA, Kalaany NY, Moffat J, et al. Ablation in mice of the mTORC components raptor, rictor, or $m L S T 8$ reveals that mTORC2 is required for signaling to Akt-FOXO and PKC $\alpha$, but not S6K1. Dev Cell. 2006;11:859-71.

131. Jacinto E, Facchinetti V, Liu D, Soto N, Wei S, Jung SY, et al. SIN1/MIP1 maintains rictor-mTOR complex integrity and regulates Akt phosphorylation and substrate specificity. Cell. 2006;127:125-37.

132. Liu P, Gan W, Chin YR, Ogura K, Guo J, Zhang J, et al. PtdIns $(3,4,5) P_{3}$-dependent activation of the mTORC2 kinase complex. Cancer Discov. 2015;5:1194-209.

133. Urbanska M, Gozdz A, Swiech LJ, Jaworski J. Mammalian target of rapamycin complex 1 (mTORC1) and 2 (mTORC2) control the dendritic arbor morphology of hippocampal neurons. J Biol Chem. 2012;287:30240-56.

134. Bozulic L, Surucu B, Hynx D, Hemmings BA. PKB $\alpha /$ Akt1 acts downstream of DNA-PK in the DNA doublestrand break response and promotes survival. Mol Cell. 2008;30:203-13.

135. Jethwa N, Chung GHC, Lete MG, Alonso A, Byrne RD, Calleja V, et al. Endomembrane PtdIns $(3,4,5) P_{3}$ activates the PI3K-Akt pathway. J Cell Sci. 2015;128:3456-65.

136. Irvine RF. Nuclear inositide signalling -- expansion, structures and clarification. Biochim Biophys Acta. 2006;1761:505-8.

137. Levenga J, Wong H, Milstead RA, Keller BN, LaPlante LE, Hoeffer CA. AKT isoforms have distinct hippocampal expression and roles in synaptic plasticity. Elife. 2017;6:e30640.

138. Golpich M, Amini E, Hemmati F, Ibrahim NM, Rahmani B, Mohamed Z, et al. Glycogen synthase kinase-3 beta (GSK-3 $\beta$ ) signaling: implications for Parkinson's disease. Pharmacol Res. 2015;97:16-26.

139. Cohen P, Frame S. The renaissance of GSK3. Nat Rev Mol Cell Biol. 2001;2:769-76.

140. Laplante M, Sabatini DM. mTOR signaling in growth control and disease. Cell. 2012;149:274-93.

141. Liu GY, Sabatini DM. mTOR at the nexus of nutrition, growth, ageing and disease. Nat Rev Mol Cell Biol. 2020;21:183-203.

142. Menon S, Dibble CC, Talbott G, Hoxhaj G, Valvezan AJ, Takahashi H, et al. Spatial control of the TSC complex integrates insulin and nutrient regulation of mTORC1 at the lysosome. Cell. 2014;156:771-85.

143. Alessi DR, Caudwell FB, Andjelkovic M, Hemmings BA, Cohen P. Molecular basis for the substrate specificity of protein kinase B; comparison with MAPKAP kinase-1 and p70 S6 kinase. FEBS Lett. 1996;399:333-8.

144. Yaguchi M, Ikeya S, Kozaki A. The activation mechanism of plant S6 kinase (S6K), a substrate of TOR kinase, is different from that of mammalian S6K. FEBS Lett. 2020;594:776-87.

145. Jhanwar-Uniyal M, Wainwright JV, Mohan AL, Tobias ME, Murali R, Gandhi CD, et al. Diverse signaling mechanisms of mTOR complexes: mTORC1 and mTORC2 in forming a formidable relationship. Adv Biol Regul. 2019;72:51-62.

146. Yu X, Long YC, Shen HM. Differential regulatory functions of three classes of phosphatidylinositol and phosphoinositide 3-kinases in autophagy. Autophagy. 2015;11:1711-28.

147. Silva A, Naia L, Dominguez A, Ribeiro M, Rodrigues J, Vieira OV, et al. Overexpression of BDNF and fulllength TrkB receptor ameliorate striatal neural survival in Huntington's disease. Neurodegener Dis. 2015;15:207-18.

148. Jossin Y, Goffinet AM. Reelin signals through phosphatidylinositol 3-kinase and Akt to control cortical development and through mTor to regulate dendritic growth. Mol Cell Biol. 2007;27:7113-24. 
149. Schicknick H, Schott BH, Budinger E, Smalla KH, Riedel A, Seidenbecher CI, et al. Dopaminergic modulation of auditory cortex-dependent memory consolidation through mTOR. Cereb Cortex. 2008;18:2646-58.

150. Jaworski J, Sheng M. The growing role of mTOR in neuronal development and plasticity. Mol Neurobiol. 2006;34:205-19.

151. Gong R, Park CS, Abbassi NR, Tang SJ. Roles of glutamate receptors and the mammalian target of rapamycin (mTOR) signaling pathway in activity-dependent dendritic protein synthesis in hippocampal neurons. J Biol Chem. 2006;281:18802-15.

152. Noda T, Ohsumi Y. Tor, a phosphatidylinositol kinase homologue, controls autophagy in yeast. J Biol Chem. 1998;273:3963-6.

153. Piper M, Lee AC, van Horck FP, McNeilly H, Lu TB, Harris WA, et al. Differential requirement of F-actin and microtubule cytoskeleton in cue-induced local protein synthesis in axonal growth cones. Neural Dev. 2015;10:3.

154. Morita T, Sobue K. Specification of neuronal polarity regulated by local translation of CRMP2 and Tau via the mTOR-p70S6K pathway. J Biol Chem. 2009;284:27734-45.

155. Santo EE, Paik J. FOXO in neural cells and diseases of the nervous system. Curr Top Dev Biol. 2018;127:105-18.

156. Bockaert J, Marin P. mTOR in brain physiology and pathologies. Physiol Rev. 2015;95:1157-87.

157. Hilgemann DW, Feng S, Nasuhoglu C. The complex and intriguing lives of $\mathrm{PIP}_{2}$ with ion channels and transporters. Sci STKE. 2001;2001:re19.

158. Hille B, Dickson EJ, Kruse M, Vivas O, Suh BC. Phosphoinositides regulate ion channels. Biochim Biophys Acta. 2015;1851:844-56.

159. Suh BC, Inoue T, Meyer T, Hille B. Rapid chemically induced changes of PtdIns $(4,5) \mathrm{P}_{2}$ gate KCNQ ion channels. Science. 2006;314:1454-7.

160. Suh BC, Hille B. Regulation of KCNQ channels by manipulation of phosphoinositides. J Physiol. 2007;582:911-6.

161. Zhang H, Craciun LC, Mirshahi T, Rohács T, Lopes CMB, Jin T, et al. PIP ${ }_{2}$ activates KCNQ channels, and its hydrolysis underlies receptor-mediated inhibition of M currents. Neuron. 2003;37:963-75.

162. Kwon Y, Hofmann T, Montell C. Integration of phosphoinositide- and calmodulin-mediated regulation of TRPC6. Mol Cell. 2007;25:491-503.

163. Hilgemann DW, Ball R. Regulation of cardiac $\mathrm{Na}^{+}, \mathrm{Ca}^{2+}$ exchange and $\mathrm{K}_{\text {ATP }}$ potassium channels by PIP $_{2}$. Science. 1996;273:956-9.

164. Du X, Zhang H, Lopes C, Mirshahi T, Rohacs T, Logothetis DE. Characteristic interactions with phosphatidylinositol 4,5-bisphosphate determine regulation of Kir channels by diverse modulators. J Biol Chem. 2004;279:37271-81.

165. Haider S, Tarasov AI, Craig TJ, Sansom MSP, Ashcroft FM. Identification of the PIP 2 -binding site on Kir6.2 by molecular modelling and functional analysis. EMBO J. 2007;26:3749-59.

166. Vaithianathan T, Bukiya A, Liu J, Liu P, Asuncion-Chin M, Fan Z, et al. Direct regulation of BK channels by phosphatidylinositol 4,5-bisphosphate as a novel signaling pathway. J Gen Physiol. 2008;132:13-28.

167. Lu M, Hebert SC, Giebisch G. Hydrolyzable ATP and PIP ${ }_{2}$ modulate the small-conductance $\mathrm{K}^{+}$channel in apical membranes of rat cortical-collecting duct (CCD). J Gen Physiol. 2002;120:603-15.

168. Suh BC, Leal K, Hille B. Modulation of high-voltage activated $\mathrm{Ca}^{2+}$ channels by membrane phosphatidylinositol 4,5-bisphosphate. Neuron. 2010;67:224-38.

169. Rohacs T, Nilius B. Regulation of transient receptor potential (TRP) channels by phosphoinositides. Pflugers Arch. 2007;455:157-68.

170. McKemy DD, Neuhausser WM, Julius D. Identification of a cold receptor reveals a general role for TRP channels in thermosensation. Nature. 2002;416:52-8. 
171. Liu B, Qin F. Functional control of cold-and menthol-sensitive TRPM8 ion channels by phosphatidylinositol 4,5-bisphosphate. J Neurosci. 2005;25:1674-81.

172. Mandal K. Review of PIP in cellular signaling, functions and diseases. Int J Mol Sci. 2020;21:8342.

173. Janmey PA, Stossel TP. Modulation of gelsolin function by phosphatidylinositol 4,5-bisphosphate. Nature. 1987;325:362-4.

174. Tuominen EK, Holopainen JM, Chen J, Prestwich GD, Bachiller PR, Kinnunen PK, et al. Fluorescent phosphoinositide derivatives reveal specific binding of gelsolin and other actin regulatory proteins to mixed lipid bilayers. Eur J Biochem. 1999;263:85-92.

175. Bucki R, Wang YH, Yang C, Kandy SK, Fatunmbi O, Bradley R, et al. Lateral distribution of phosphatidylinositol 4,5-bisphosphate in membranes regulates formin- and ARP2/3-mediated actin nucleation. J Biol Chem. 2019;294:4704-22.

176. Goldschmidt-Clermont PJ, Machesky LM, Baldassare JJ, Pollard TD. The actin-binding protein profilin binds to PIP ${ }_{2}$ and inhibits its hydrolysis by phospholipase C. Science. 1990;247:1575-8.

177. Zhao $\mathrm{H}$, Hakala M, Lappalainen P. ADF/cofilin binds phosphoinositides in a multivalent manner to act as a $\mathrm{PIP}_{2}$-density sensor. Biophys J. 2010;98:2327-36.

178. Saarikangas J, Kourdougli N, Senju Y, Chazal G, Segerstråle M, Minkeviciene R, et al. MIM-induced membrane bending promotes dendritic spine initiation. Dev Cell. 2015;33:644-59.

179. Spillane M, Ketschek A, Donnelly CJ, Pacheco A, Twiss JL, Gallo G. Nerve growth factor-induced formation of axonal filopodia and collateral branches involves the intra-axonal synthesis of regulators of the actinnucleating Arp2/3 complex. J Neurosci. 2012;32:17671-89.

180. Ketschek A, Gallo G. Nerve growth factor induces axonal filopodia through localized microdomains of phosphoinositide 3-kinase activity that drive the formation of cytoskeletal precursors to filopodia. J Neurosci. 2010;30:12185-97.

181. Luikart BW, Zhang W, Wayman GA, Kwon CH, Westbrook GL, Parada LF. Neurotrophin-dependent dendritic filopodial motility: a convergence on PI3K signaling. J Neurosci. 2008;28:7006-12.

182. Jansen LA, Mirzaa GM, Ishak GE, O’Roak BJ, Hiatt JB, Roden WH, et al. PI3K/AKT pathway mutations cause a spectrum of brain malformations from megalencephaly to focal cortical dysplasia. Brain. 2015;138:1613-28.

183. Turner TN, Hormozdiari F, Duyzend MH, McClymont SA, Hook PW, Iossifov I, et al. Genome sequencing of autism-affected families reveals disruption of putative noncoding regulatory DNA. Am J Hum Genet. 2016;98:58-74.

184. Pinto D, Delaby E, Merico D, Barbosa M, Merikangas A, Klei L, et al. Convergence of genes and cellular pathways dysregulated in autism spectrum disorders. Am J Hum Genet. 2014;94:677-94.

185. Gross C, Raj N, Molinaro G, Allen AG, Whyte AJ, Gibson JR, et al. Selective role of the catalytic PI3K subunit p110 $\beta$ in impaired higher order cognition in fragile X syndrome. Cell Rep. 2015;11:681-8.

186. Kumari D, Bhattacharya A, Nadel J, Moulton K, Zeak NM, Glicksman A, et al. Identification of fragile $\mathrm{X}$ syndrome specific molecular markers in human fibroblasts: a useful model to test the efficacy of therapeutic drugs. Hum Mutat. 2014;35:1485-94.

187. Gross C, Bassell GJ. Excess protein synthesis in FXS patient lymphoblastoid cells can be rescued with a p110ß-selective inhibitor. Mol Med. 2012;18:336-45.

188. Poopal AC, Schroeder LM, Horn PS, Bassell GJ, Gross C. Increased expression of the PI3K catalytic subunit p110 $\delta$ underlies elevated S6 phosphorylation and protein synthesis in an individual with autism from a multiplex family. Mol Autism. 2016;7:3.

189. Law AJ, Wang Y, Sei Y, O’Donnell P, Piantadosi P, Papaleo F, et al. Neuregulin 1-ErbB4-PI3K signaling in schizophrenia and phosphoinositide 3-kinase-p110 $\delta$ inhibition as a potential therapeutic strategy. Proc Natl Acad Sci U S A. 2012;109:12165-70. 
190. Cukier HN, Skaar DA, Rayner-Evans MY, Konidari I, Whitehead PL, Jaworski JM, et al. Identification of chromosome 7 inversion breakpoints in an autistic family narrows candidate region for autism susceptibility. Autism Res. 2009;2:258-66.

191. Rivière JB, Mirzaa GM, O’Roak BJ, Beddaoui M, Alcantara D, Conway RL, et al. De novo germline and postzygotic mutations in AKT3, PIK3R2 and PIK3CA cause a spectrum of related megalencephaly syndromes. Nat Genet. 2012;44:934-40.

192. Gupta AR, Pirruccello M, Cheng F, Kang HJ, Fernandez TV, Baskin JM, et al. Rare deleterious mutations of the gene EFR3A in autism spectrum disorders. Mol Autism. 2014;5:31.

193. Usui D, Shimada S, Shimojima K, Sugawara M, Kawasaki H, Shigematu H, et al. Interstitial duplication of 2q32.1-q33.3 in a patient with epilepsy, developmental delay, and autistic behavior. Am J Med Genet A. 2013;161A:1078-84.

194. Satterstrom FK, Kosmicki JA, Wang J, Breen MS, De Rubeis S, An JY, et al. Large-scale exome sequencing study implicates both developmental and functional changes in the neurobiology of autism. Cell. 2020;180:568-84.e23.

195. Yehia L, Keel E, Eng C. The clinical spectrum of PTEN mutations. Annu Rev Med. 2020;71:103-16.

196. Hansen-Kiss E, Beinkampen S, Adler B, Frazier T, Prior T, Erdman S, et al. A retrospective chart review of the features of PTEN hamartoma tumour syndrome in children. J Med Genet. 2017;54:471-8.

197. Kwon CH, Luikart BW, Powell CM, Zhou J, Matheny SA, Zhang W, et al. Pten regulates neuronal arborization and social interaction in mice. Neuron. 2006;50:377-88.

198. Williams MR, DeSpenza T Jr, Li M, Gulledge AT, Luikart BW. Hyperactivity of newborn Pten knock-out neurons results from increased excitatory synaptic drive. J Neurosci. 2015;35:943-59.

199. Skelton PD, Frazel PW, Lee D, Suh H, Luikart BW. Pten loss results in inappropriate excitatory connectivity. Mol Psychiatry. 2019;24:1627-40.

200. Getz SA, DeSpenza T Jr, Li M, Luikart BW. Rapamycin prevents, but does not reverse, aberrant migration in Pten knockout neurons. Neurobiol Dis. 2016;93:12-20.

201. Luikart BW, Schnell E, Washburn EK, Bensen AL, Tovar KR, Westbrook GL. Pten knockdown in vivo increases excitatory drive onto dentate granule cells. J Neurosci. 2011;31:4345-54.

202. Cossec JC, Lavaur J, Berman DE, Rivals I, Hoischen A, Stora S, et al. Trisomy for synaptojanin1 in Down syndrome is functionally linked to the enlargement of early endosomes. Hum Mol Genet.2012;21:3156-72.

203. Volpatti JR, Al-Maawali A, Smith L, Al-Hashim A, Brill JA, Dowling JJ. The expanding spectrum of neurological disorders of phosphoinositide metabolism. Dis Model Mech. 2019;12:dmm038174.

204. Miranda AM, Herman M, Cheng R, Nahmani E, Barrett G, Micevska E, et al. Excess synaptojanin 1 contributes to place cell dysfunction and memory deficits in the aging hippocampus in three types of Alzheimer's disease. Cell Rep. 2018;23:2967-75.

205. Voronov SV, Frere SG, Giovedi S, Pollina EA, Borel C, Zhang H, et al. Synaptojanin 1-linked phosphoinositide dyshomeostasis and cognitive deficits in mouse models of Down's syndrome. Proc Natl Acad Sci U S A. 2008;105:9415-20.

206. Zhu L, Zhong M, Zhao J, Rhee H, Caesar I, Knight EM, et al. Reduction of synaptojanin 1 accelerates $\mathrm{A} \beta$ clearance and attenuates cognitive deterioration in an Alzheimer mouse model. J Biol Chem. 2013;288:32050-63.

207. Dyment DA, Smith AC, Humphreys P, Schwartzentruber J, Beaulieu CL, FORGE Canada Consortium, et al. Homozygous nonsense mutation in SYNJ1 associated with intractable epilepsy and tau pathology. Neurobiol Aging. 2015;36:1222.e1-5.

208. Krebs CE, Karkheiran S, Powell JC, Cao M, Makarov V, Darvish H, et al. The Sac1 domain of SYNJ1 identified mutated in a family with early-onset progressive Parkinsonism with generalized seizures. Hum Mutat. 2013;34:1200-7. 
209. Al Zaabi N, Al Menhali N, Al-Jasmi F. SYNJ1 gene associated with neonatal onset of neurodegenerative disorder and intractable seizure. Mol Genet Genomic Med. 2018;6:109-13.

210. Hardies K, Cai Y, Jardel C, Jansen AC, Cao M, May P, et al. Loss of SYNJ1 dual phosphatase activity leads to early onset refractory seizures and progressive neurological decline. Brain. 2016;139:2420-30.

211. Xie T, Deng L, Mei P, Zhou Y, Wang B, Zhang J, et al. Genome-wide association study combining pathway analysis for typical sporadic amyotrophic lateral sclerosis in Chinese Han populations. Neurobiol Aging. 2014;35:1778.e9-23.

212. Henkel K, Danek A, Grafman J, Butman J, Kassubek J. Head of the caudate nucleus is most vulnerable in chorea-acanthocytosis: a voxel-based morphometry study. Mov Disord. 2006;21:1728-31.

213. Tomemori Y, Ichiba M, Kusumoto A, Mizuno E, Sato D, Muroya S, et al. A gene-targeted mouse model for chorea-acanthocytosis. J Neurochem. 2005;92:759-66.

214. Luo FM, Deng MX, Yu R, Liu L, Fan LL. Case report: chorea-acanthocytosis presents as epilepsy in a consanguineous family with a nonsense mutation of in VPS13A. Front Neurosci. 2021;15:604715.

215. Lang F, Pelzl L, Schols L, Hermann A, Foller M, Schaffer TE, et al. Neurons, erythrocytes and beyond -the diverse functions of chorein. Neurosignals. 2017;25:117-26.

216. Park JS, Halegoua S, Kishida S, Neiman AM. A conserved function in phosphatidylinositol metabolism for mammalian Vps13 family proteins. PLoS One. 2015;10:e0124836.

217. Föller M, Hermann A, Gu S, Alesutan I, Qadri SM, Borst O, et al. Chorein-sensitive polymerization of cortical actin and suicidal cell death in chorea-acanthocytosis. FASEB J. 2012;26:1526-34.

218. Shadrina MI, Shulskaya MV, Klyushnikov SA, Nikopensius T, Nelis M, Kivistik PA, et al. ITPR1 gene p.Val1553Met mutation in Russian family with mild spinocerebellar ataxia. Cerebellum Ataxias. 2016;3:2.

219. Ando H, Hirose M, Mikoshiba K. Aberrant $\mathrm{IP}_{3}$ receptor activities revealed by comprehensive analysis of pathological mutations causing spinocerebellar ataxia 29. Proc Natl Acad Sci U S A. 2018;115:12259-64.

220. Miyamoto Y, Torii T, Eguchi T, Nakamura K, Tanoue A, Yamauchi J. Hypomyelinating leukodystrophyassociated missense mutant of FAM126A/hyccin/DRCTNNB1A aggregates in the endoplasmic reticulum. J Clin Neurosci. 2014;21:1033-9. 